Article

\title{
Synthesis of New 3-Heteroarylindoles as Potential Anticancer Agents
}

\author{
Abdou O. Abdelhamid ${ }^{1}$, Sobhi M. Gomha ${ }^{1, *}$, Nadia A. Abdelriheem ${ }^{1}$ and Saher M. Kandeel ${ }^{2}$ \\ 1 Department of Chemistry, Faculty of Science, Cairo University, Giza 12613, Egypt; \\ abdelhamid45@gmail.com (A.O.A.); nadia.abdelhamid5@gmail.com (N.A.A.) \\ 2 Chemistry of Natural Compounds, Department National Research Center, Dokki 12622, Egypt; \\ SaherKamel@yahoo.com \\ * Correspondence: s.m.gomha@gmail.com; Tel.: +20-2-3567-6573; Fax: +20-2-3572-7556
}

Academic Editor: Richard A. Bunce

Received: 25 May 2016; Accepted: 12 July 2016; Published: 16 July 2016

\begin{abstract}
H-Indol-3-yl)-5-( $p$-tolyl)-4,5-dihydro-1H-pyrazol-1-yl)-4-substituted-5-(substituted diazenyl)thiazoles and 2-(1H-indol-3-yl)-9-substituted-4,7-disubstituted pyrido[3,2-e][1,2,4]triazolo [4,3-a]pyrimidin-5(7H)-ones were synthesized via reaction of hydrazonoyl halides with each of 3-(1H-indol-2-yl)-5-( $p$-tolyl)-4,5-dihydro-1H-pyrazole-1-carbothioamide and 7-(1H-indol-3-yl)-2thioxo-5-substituted-2,3-dihydropyrido[2,3- $d$ ] pyrimidin-4(1H)-ones, respectively. Also, hydrazonoyl halides were reacted with $N^{\prime}$-(1-(1H-indol-3-yl)ethylidene)-2-cyanoacetohydrazide to afford 1,3,4-thiadiazole derivatives. Structures of the new synthesis were elucidated on the basis of elemental analysis, spectral data, and alternative synthetic routes whenever possible. Fifteen of the new compounds have been evaluated for their antitumor activity against the MCF-7 human breast carcinoma cell line. The results indicated that many of the tested compounds showed moderate to high anticancer activity when compared with doxorubicin as a reference drug.
\end{abstract}

Keywords: thiazoles; pyrazoles; coupling reactions; thiosemicarbazides; molecular docking; anti-cancer activity

\section{Introduction}

The wide-ranging biological activity associated with indole derivatives, both naturally occurring and synthetic, ensures that the synthesis of indole derivatives remains a topic of current interest [1-4]. Monoindole and bisindole have been intensively studied and the results revealed that most of them have biological activities; for example, indole-3-carbinol, found in Brassica plants, is a potential cancer protective agent $[5,6]$. Thiazoles can be found in drug development for the treatment of allergies [7], hypertension [8], inflammation [9], schizophrenia [10], bacterial infections [11], HIV [12], sleep disorders [13], and for the treatment of pain [14], as fibrinogen receptor antagonists with antithrombotic activity [15] and as new inhibitors of bacterial DNA gyrase B [16]. The 1,2,4-triazolopyrimidines have also attracted growing interest due to their important pharmacological activities, such as antitumor, antimalarial, antimicrobial, anti-inflammatory, and antifungal activity, as well as macrophage activation [17-22]. 1,3,4-Thiadiazole derivatives have attracted considerable interest owing to their wide ranging biological activities such as antibacterial, antifungal, antituberculosis, antihepatitis B viral, antileishmanial, anti-inflammatory, analgesic, CNS depressant, anticancer, antioxidant, antidiabetic, molluscicidal, antihypertensive, diuretic, analgesic, antimicrobial, antitubercular, and anticonvulsant activities [23-32]. In light of these facts, we have synthesized some new thiazole, dihydropyrido[3,2-e][1,2,4] triazolo[4,3-a]pyrimidine and 1,3,4-thiadiazole derivatives using 3 -acetylindole as a common precursor and screened these compounds for their anticancer activities. A literature survey showed that many derivatives of thiazole and 1,3,4-thiadiazole have antitumor 
activity with excellent $\mathrm{IG}_{50}$ and $\mathrm{IC}_{50}$ as depicted in Figure 1 [33-37]. In view of these facts, we report herein the synthesis of a new series of thiazoles and 1,3,4-thiadiazoles bearing indole moiety for the examination of their antitumor activity against the MCF-7 human breast carcinoma cell line.

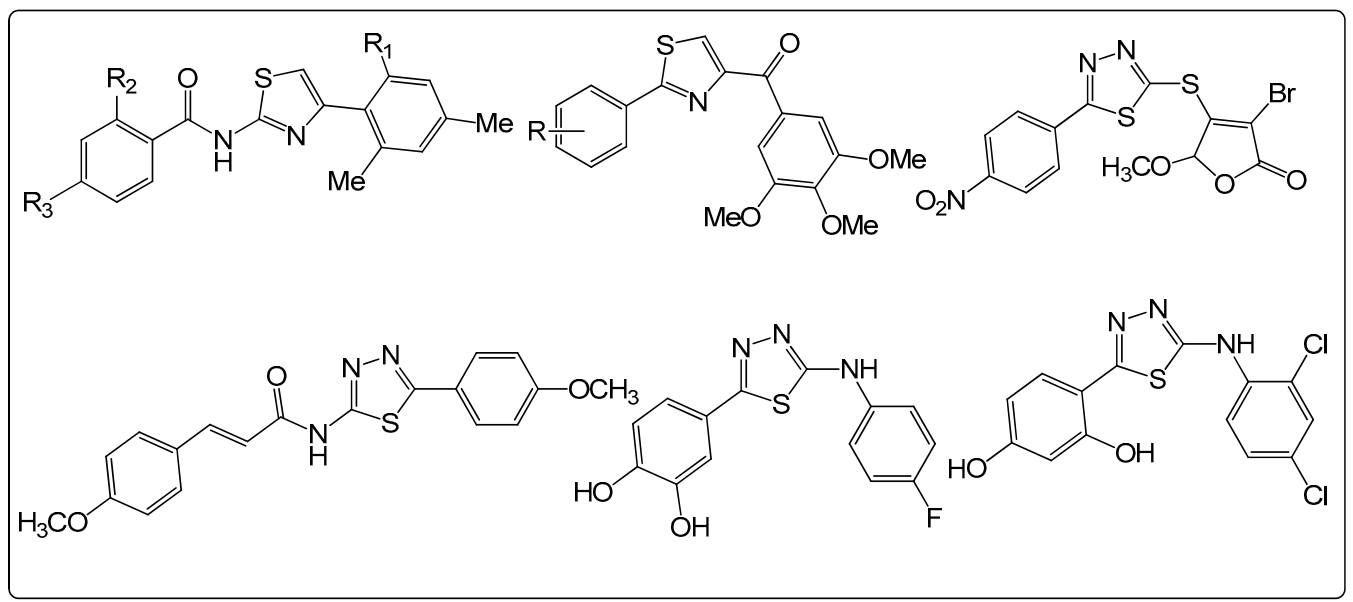

Figure 1. Lead compounds among thiazole and thiadiazole derivatives with anticancer activity.

\section{Results and Discussion}

\subsection{Chemistry}

1-(1H-Indol-3-yl)-3-( $p$-tolyl)prop-2-en-1-one (3a) [38] and 3-(4-chlorophenyl)-1-(1H-indol-3-yl) prop-2-en-1-one (3b) [39] were prepared as reported in the literature from reaction of 3-acetylindole (1) with $p$-tolualdehyde (2a) and 4-chlorobenzaldehyde ( $\mathbf{2 b}$ ), respectively (Scheme 1 ).<smiles>CC(=O)c1c[nH]c2ccccc12</smiles>

Scheme 1. Synthesis of pyrazole-1-carbothioamide 5 and pyrido[2,3- $d$ ]pyrimidinthione derivatives $7 \mathbf{a}, \mathbf{b}$.

Treatment of 3-aryl-1-(1H-indol-3-yl)prop-2-en-1-ones 3a,b with thiosemicarbazide (4) afforded 3-(1H-indol-2-yl)-5-( $p$-tolyl)-4,5-dihydro-1H-pyrazole-1-carbothioamide (5). Similar treatment with 6-amino-2-thioxo-2,3-dihydropyrimidin-4(1H)-one (6) generated 5-aryl-7-(1H-indol-3-yl)-2-thioxo2,3-dihydropyrido[2,3-d]pyrimidin-4(1H)-ones $\mathbf{7 a}, \mathbf{b}$, respectively (Scheme 1$)$. Structures 5 and $\mathbf{7}$ were elucidated by elemental analysis, spectral data, and chemical transformation.

Compound 5 was reacted with the appropriate keto-hydrazonoyl halides $\mathbf{8 a}-\mathbf{e}$ in dioxane containing a catalytic amount of TEA, to afford 2-(3-(1H-indol-3-yl)-5-( $p$-tolyl)-4,5-dihydro1H-pyrazol-1-yl)-5-(aryldiazenyl)-4-substituted thiazoles 12a-e. Coupling of 2-(3-(1H-indol-3-yl)-5( $p$-tolyl)-4,5-dihydro-1H-pyrazol-1-yl)-4-phenylthiazole (15e)[prepared by reaction of 5 with phenacyl bromide (14)] with benzenediazonium chloride in ethanolic sodium acetate solution at $0{ }^{\circ} \mathrm{C}$ afforded 
a product identical to 12e in all aspects ( $\mathrm{mp}$, mixed $\mathrm{mp}$, and spectra). In light of these results, the mechanism outlined in Scheme 2 seems to be the most plausible pathway for the formation of 12a from the reaction of 5 with 8a. The reaction involves initial formation of thiohydrazonate 10, which undergoes cyclization as soon as it is formed to yield the intermediate 11. The latter loses one molecule of water to give final product 12a. Alternatively, 1,3-dipolar cycloaddition of nitrilimine 9a [prepared in situ from $8 \mathbf{a}$ with triethylamine] to the $\mathrm{C}=\mathrm{S}$ double bond of $\mathbf{5}$ could also lead to $\mathbf{1 0}$. The formation of $\mathbf{1 1}$ and $\mathbf{1 2}$ are similar to the previously reported reactions of hydrazonoyl chloride with 1-phenyl-1,4-dihydrotetrazole-5-thione [40] and 5-phenyl-1,3,4thiadiazole-2(3H)-thione [41]. Another possible product, 1-(5-(3-(1H-indol-3-yl)-5-( $p$-tolyl)-4,5dihydro-1H-pyrazol-1-yl)-5-amino-4-phenyl-4,5-dihydro-1,3,4-thiadiazol-2-yl)ethan-1-one (13), was ruled out by elemental analysis and spectral data. Analogously, treatment of the appropriate 5 with each of $\mathbf{8 b}$-e gave 2-(3-(1H-indol-3-yl)-5-( $p$-tolyl)-4,5-dihydro- $1 H$-pyrazol-1-yl)-4-substituted-5(substituted-diazenyl)thiazoles 12b-e, respectively, in good yield (Scheme 2).

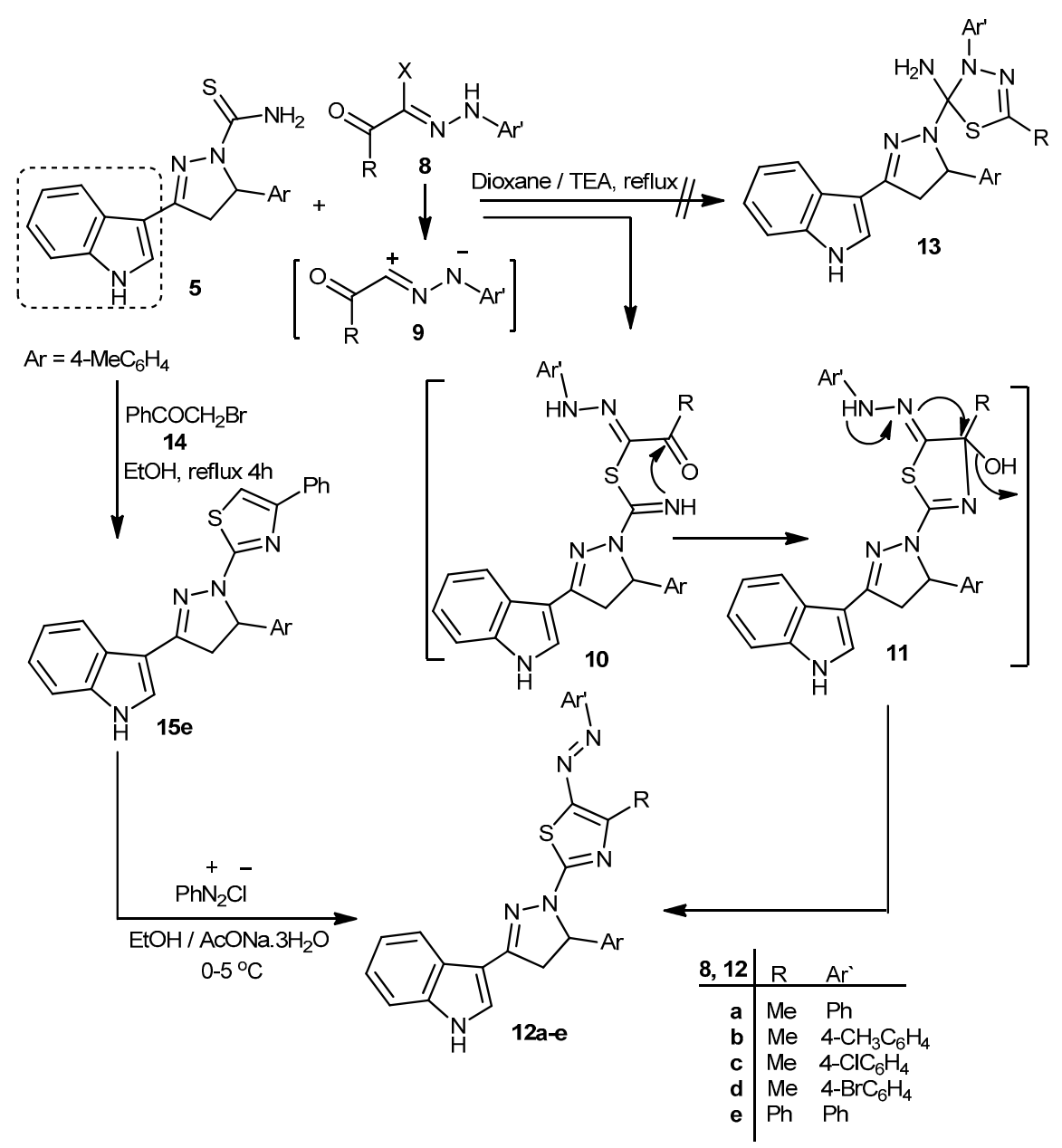

Scheme 2. Synthesis of arylazothiazole derivatives 12a-e.

Treatment of the appropriate 5-aryl-7-(1H-indol-3-yl)-2-thioxo-2,3-dihydropyrido[2,3- $d$ ] pyrimidin-4(1H)-ones $\mathbf{7 a}$ or $\mathbf{7 b}$ with the appropriate hydrazonoyl halides $\mathbf{8 a} \mathbf{a} \mathbf{j}$ in dioxane containing TEA under reflux gave 2-(1H-indol-3-yl)-9-substituted-4,7-disubstituted pyrido[3,2-e] $[1,2,4]$ triazolo[4,3-a]pyrimidin-5(7H)-ones 19a-1, respectively (Scheme 3). Structure 19 was elucidated by elemental analysis, spectral data, and alternative synthetic routes. Thus, treatment of 7-amino-3-substituted-1-phenyl-[1,2,4]triazolo[4,3-a]pyrimidin-5(1H)-ones 20a,e, i [42] with chalcone 
3a in boiling acetic acid made products identical in all respects (mp., mixed mp., and spectra) with the corresponding 19a,e,i.

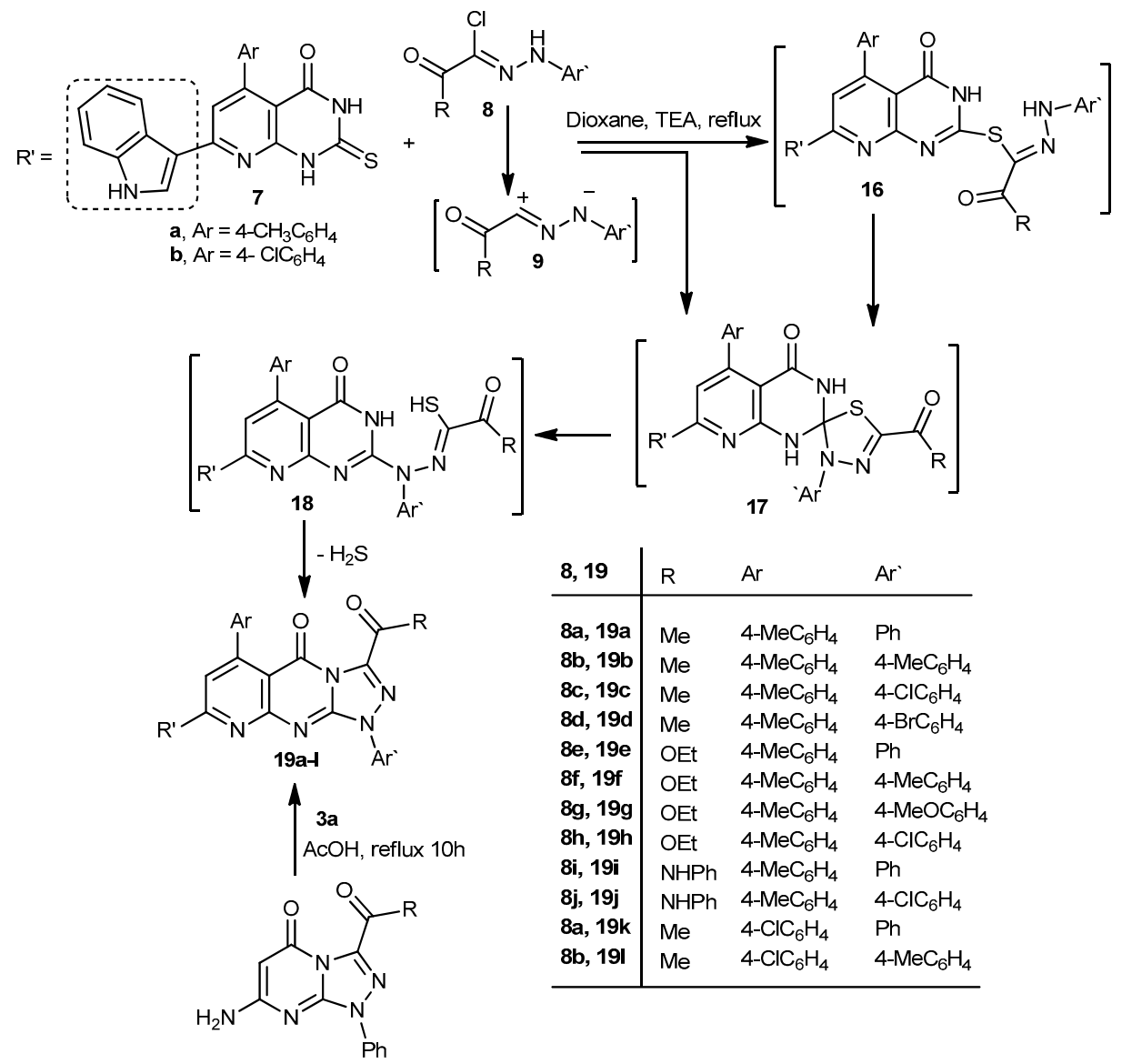

Scheme 3. Synthesis of triazolopyridopyrimidinones 19a-1.

The mechanism in Scheme 3 outlines what seems to be the most plausible pathway for the formation of 19 from the reaction of thione 7 with 8 via two pathways. In the first, 1,3-addition of the thiol tautomer $\mathbf{7}$ to the nitrilimine $\mathbf{9}$ would give the thiohydrazonate ester $\mathbf{1 6}$ which would undergo nucleophilic cyclization to yield spiro compounds 17. Ring opening to give $\mathbf{1 8}$ followed by cyclization with loss of hydrogen sulfide would then yield 19. In the second pathway, an initial 1,3-cycloaddition of nitrilimine 9 to the $C=S$ double bond of 7 would give 17 directly (Scheme 3). Attempts to isolate the thiohydrazonate ester 16, spiro intermediate 17 and thiohydrazide 18 did not succeed, even under mild conditions as they readily undergo in situ cyclization followed by elimination of hydrogen sulfide to give the final product 19. This structural assignment is also consistent with literature reports, which indicate that reaction of hydrazonoyl halides with 2-thioxo-pyrimidin-4-one yielded regioselectively the corresponding 1,2,4-triazolo[4,3-a]pyrimidin- 5-one derivatives [42].

Finally, 2-cyanoacetohydrazide (21) was reacted with 3-acetylindole (1) in boiling ethanol containing a catalytic amount of acetic acid to afford $N^{\prime}-(1-(1 H$-indol-3-yl) ethylidene)-2cyanoacetohydrazide (22) in good yield (Scheme 4). Structure 22 was elucidated by elemental analysis, spectral data, and chemical transformation. Treatment of 22 with phenylisothiocyanate (23) in DMF in the presence of potassium hydroxide at room temperature followed by acid work-up yielded the thioanilide 25 . Refluxing thioanilide 25 with the appropriate hydrazonoyl chlorides $8 \mathbf{a}, \mathbf{e}, \mathbf{i}$ in ethanolic triethylamine, gave the respective 1,3,4-thiadiazoles 27a-c. (Scheme 4). Thiadiazoles 27a-c were elucidated by elemental analysis and spectral data. 

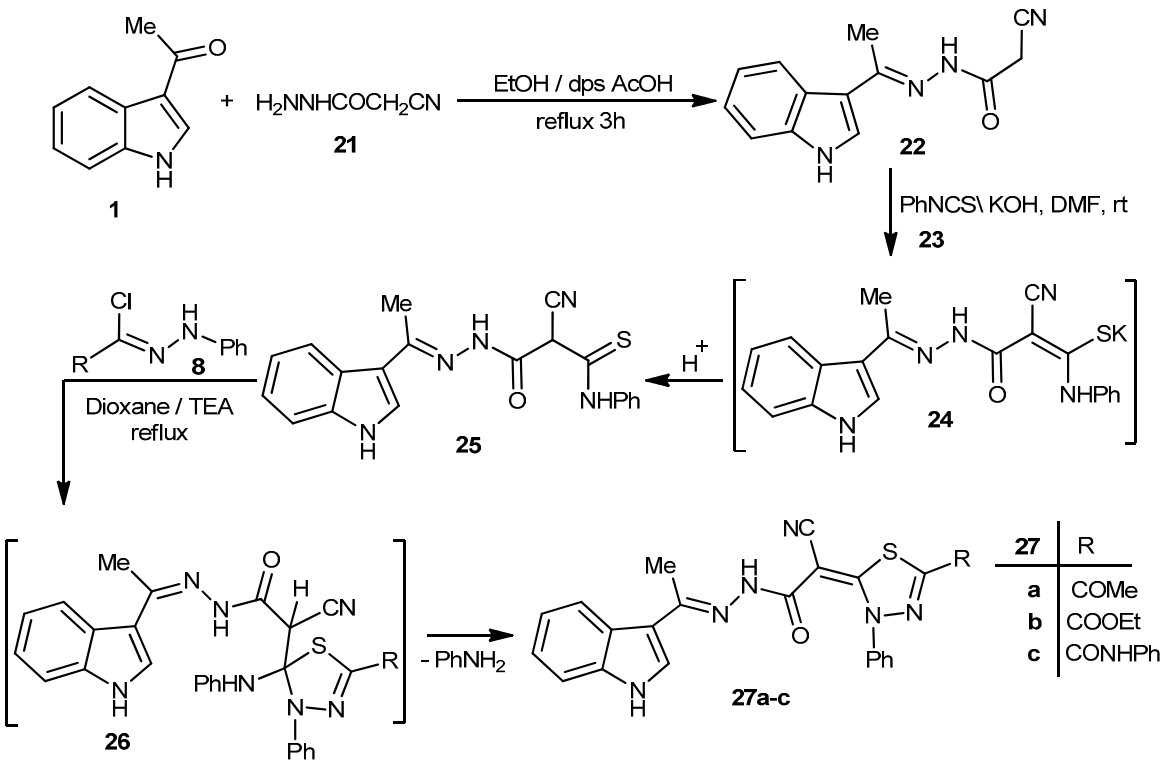

Scheme 4. Synthesis of thiadiazoles $27 \mathbf{a}-\mathbf{c}$.

\subsection{Biological Screening (Cytotoxic Activity)}

The in vitro growth inhibitory rates (\%) and inhibitory growth activity (as measured by $\mathrm{IC}_{50}$ ) of the newly synthesized compounds were determined against the MCF-7 human breast carcinoma cell line in comparison with the well-known anticancer drug doxorubicin as the standard, using the MTT viability assay. Data generated were used to plot a dose response curve from which the concentration $(\mu \mathrm{M})$ of test compounds required to kill $50 \%$ of cell population $\left(\mathrm{IC}_{50}\right)$ was determined. Cytotoxic activity was expressed as the mean $\mathrm{IC}_{50}$ of three independent experiments. The difference between inhibitory activities of all compounds with different concentrations was statistically significant $p<0.001$.

The results revealed that the tested compounds showed high variation in the inhibitory growth rates and activities against the tested tumor cell lines in a concentration dependent manner compared to the reference drug as shown in Table 1 and Figure 2.

Table 1. The antitumor activities of the tested compounds compared with reference doxorubicin evaluated using MTT assay on the MCF-7 breast cancer cell line.<smiles>[R]c1nc(N2N=C(c3c[nH]c4ccccc34)CC2c2ccc(C)cc2)sc1N=N[Ga]</smiles><smiles>[R]c1nn([Al])c2nc3nc(-c4c[nH]c5ccccc45)cc(-c4ccc(C)cc4)c3c(=O)n12</smiles><smiles>[Z10]CC(=O)N/N=C(\C)c1c[nH]c2ccccc12</smiles>

\begin{tabular}{cccc}
\hline Compound No. & $\mathbf{R}$ & $\mathbf{A r}$ & IC $_{\mathbf{5 0}}(\mu \mathbf{M})$ \\
\hline $\mathbf{1 2 a}$ & $\mathrm{CH}_{3}$ & $\mathrm{Ph}$ & 4.92 \\
$\mathbf{1 2 b}$ & $\mathrm{CH}_{3}$ & $4-\mathrm{MeC}_{6} \mathrm{H}_{4}$ & 0.95 \\
$\mathbf{1 2 c}$ & $\mathrm{CH}_{3}$ & $4-\mathrm{ClC}_{6} \mathrm{H}_{4}$ & 14.52 \\
$\mathbf{1 2 e}$ & $\mathrm{Ph}$ & $\mathrm{Ph}$ & 19.44 \\
\hline
\end{tabular}


Table 1. Cont.

\begin{tabular}{cccc}
\hline Compound No. & $\mathbf{R}$ & $\mathbf{A r}$ & $\mathbf{I C}_{\mathbf{5 0}}(\mu \mathbf{M})$ \\
\hline $\mathbf{1 9 a}$ & $\mathrm{CH}_{3} \mathrm{CO}$ & $\mathrm{Ph}$ & 6.88 \\
$\mathbf{1 9 b}$ & $\mathrm{CH}_{3} \mathrm{CO}$ & $4-\mathrm{MeC}_{6} \mathrm{H}_{4}$ & 4.68 \\
$\mathbf{1 9 c}$ & $\mathrm{CH}_{3} \mathrm{CO}$ & $4-\mathrm{ClC}_{6} \mathrm{H}_{4}$ & 69.85 \\
$\mathbf{1 9}$ & $\mathrm{CH}_{3} \mathrm{CH}_{2} \mathrm{OCO}$ & $\mathrm{Ph}$ & 4.83 \\
$\mathbf{1 9 f}$ & $\mathrm{CH}_{3} \mathrm{CH}_{2} \mathrm{OCO}$ & $4-\mathrm{MeC}_{6} \mathrm{H}_{4}$ & 5.49 \\
$\mathbf{1 9 g}$ & $\mathrm{CH}_{3} \mathrm{CH}_{2} \mathrm{OCO}$ & $4-\mathrm{MeOC}_{6} \mathrm{H}_{4}$ & 3.05 \\
$\mathbf{1 9 h}$ & $\mathrm{CH}_{3} \mathrm{CH}_{2} \mathrm{OCO}$ & $4-\mathrm{ClC}_{6} \mathrm{H}_{4}$ & 18.61 \\
$\mathbf{1 9 i}$ & $\mathrm{PhNHCO}_{\mathbf{2 7}}$ & $\mathrm{Ph}$ & 6.07 \\
$\mathbf{2 7 b}$ & $\mathrm{CH}_{3} \mathrm{CO}$ & $\mathrm{Ph}$ & 2.04 \\
$\mathbf{2 7 c}$ & $\mathrm{CH}_{3} \mathrm{CH}_{2} \mathrm{OCO}$ & $\mathrm{Ph}$ & 1.01 \\
Doxorubicin & $\mathrm{PhNHCO}^{2} \mathrm{Ph}$ & 1.27 \\
\hline
\end{tabular}

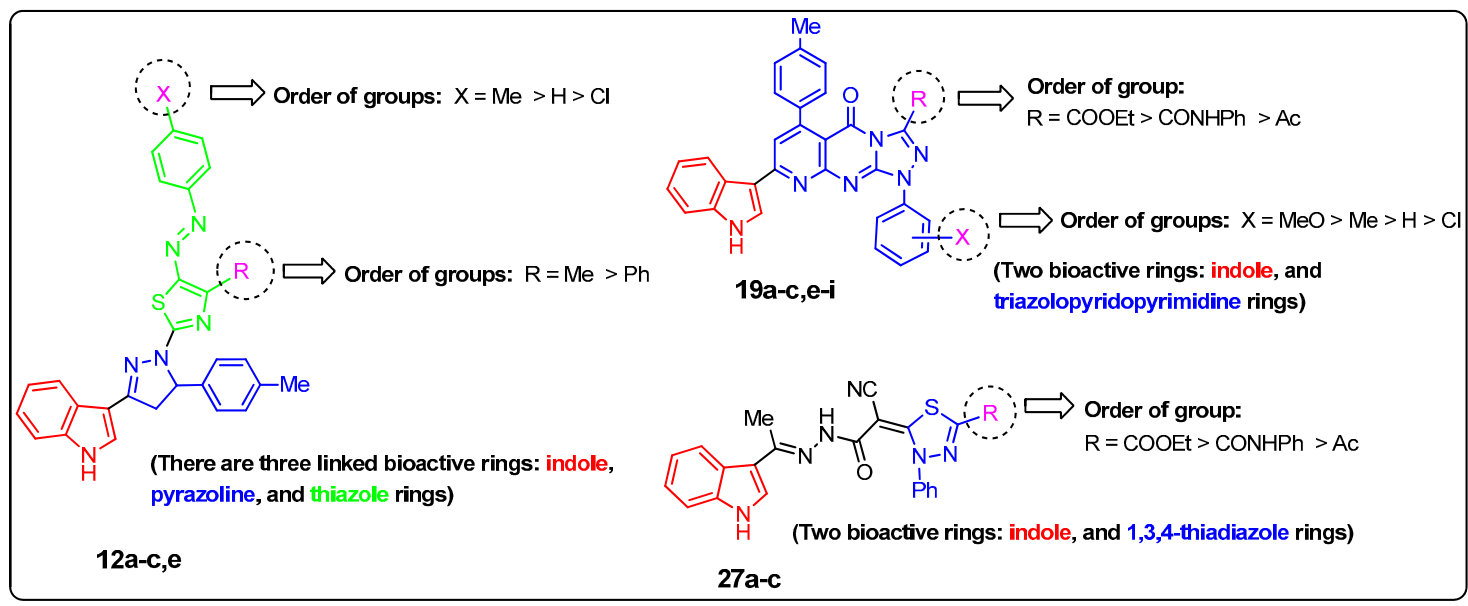

Figure 2. Activities of tested compounds against the MCF-7 breast cancer cell line.

The descending order of activity of the newly synthesized compounds was as follows: $\mathbf{1 2} \mathbf{b}>\mathbf{2 7 b}$ $>27 \mathrm{c}>27 \mathrm{a}>19 \mathrm{~g}>19 \mathrm{~b}>19 \mathrm{e}>12 \mathrm{a}>19 \mathrm{f}>19 \mathrm{i}>19 \mathrm{a}>12 \mathrm{c}>19 \mathrm{~h}>12 \mathrm{e}>19 \mathrm{c}$.

\subsection{Examination of the Compound Activities Leads to the Following Conclusions}

- The activities of the synthesized compounds depend on the structural skeleton and electronic environment of the molecules.

- $\quad$ Based on our limited study, the 1,3,4-thiadiazole ring as in $\mathbf{2 7}$ has in vitro inhibitory activity greater than the 1,3-thiazole ring in $\mathbf{1 2}$ and more than the triazolopyridopyrimidine ring in $\mathbf{1 9 .}$

\subsubsection{For the 1,3-Thiazole Ring 12a-c,e}

- The in vitro inhibitory activity of the 4-methylthiazole is greater than 4-phenylthiazole (12a $>\mathbf{1 2 e})$. This may be due to the positive inductive effect (+I effect) of the methyl group (increase activity) or the steric effect caused by phenyl group (decrease activity).

- The introduction of electron-donating group (methyl) at C4 of the phenyl group at position 4 in the 1,3-thiazole ring enhances the antitumor activity. In contrast, introduction of an electron-withdrawing group (chlorine) decreases the antitumor activity $(\mathbf{1 2 b}>\mathbf{1 2 a}>\mathbf{1 2 c})$.

\subsubsection{For Triazolopyridopyrimidines $19 \mathbf{a}-\mathbf{c}, \mathbf{e}-\mathbf{i}$}

- For substituent at position 3: the ester group $\left(\mathrm{CO}_{2} \mathrm{Et}\right)$ gives higher activity than the amide group $(\mathrm{CONHPh})$ or the acetyl group (Ac) $(19 \mathbf{e}>19 \mathbf{i}>19 \mathbf{a})$. 
- Generally, on fixing the substituents at position 3, the electron-donating group (methyl or methoxy) at $\mathrm{C} 4$ of the phenyl ring enhances the antitumor activity while the electron-withdrawing group (chlorine) decreases the antitumor activity $(19 \mathrm{~b}>19 \mathrm{a}>19 \mathrm{c}$ and $19 \mathrm{~g}>19 \mathrm{f}>19 \mathrm{e}>19 \mathrm{~h})$.

\subsubsection{For $1,3,4$-Thiadiazoles $\mathbf{2 7 a - c}$}

- The in vitro inhibitory activity of compounds with substituents at position 5 are in the order of: COOEt $>\mathrm{CONHPh}>\mathrm{CH}_{3} \mathrm{CO}(27 \mathbf{b}>27 \mathrm{c}>27 \mathbf{a})$.

\section{Experimental}

\subsection{Chemistry}

All melting points were measured on an Electro thermal IA 9000 series digital melting point apparatus (Bibby Sci. Lim. Stone, Staffordshire, UK). The IR spectra were recorded on potassium bromide discs using a PyeUnicam SP 3300 or Shimadzu FT IR 8101 PC infrared spectrophotometer (Shimadzu, Tokyo, Japan). The NMR Spectra were recorded at $270 \mathrm{MHz}$ on a Varian Mercury VX-300 NMR spectrometer (Varian, Inc., Karlsruhe, Germany). NMR spectra were recorded on a Varian Mercury VX-300 NMR spectrometer (Bruker BioSpin GmbH, Rheinstetten, Germany) operating at $300 \mathrm{MHz}\left({ }^{1} \mathrm{H}-\mathrm{NMR}\right)$ and run in deuterated dimethylsulfoxide (DMSO- $\left.d_{6}\right)$. Chemical shifts were related to that of the solvent. ${ }^{13} \mathrm{C}-\mathrm{NMR}$ spectra were recorded at $75 \mathrm{MHz}$. Mass spectra were recorded on a Shimadzu GCMS-QP1000 EX mass spectrometer (Tokyo, Japan) at $70 \mathrm{eV}$. Elemental analyses and the biological evaluation of the products were carried out at the Microanalytical Centre of Cairo University, Giza, Egypt. All reactions were followed by TLC (silica gel coated aluminum sheets 60 F254, Merck, Merck \& Co., Inc., Kenilworth, NJ, USA). Hydrazonoyl halides were prepared as reported in the literature [43-46].

\subsubsection{Synthesis of 3-(1H-Indol-3-yl)-5-(p-tolyl)-4,5-dihydro-1H-pyrazole-1-carbothioamide (5)}

To a mixture of 1-(1H-indol-3-yl)-3-(p-tolyl)prop-2-en-1-one (3a) (2.61 g, $10 \mathrm{mmol})$ and thiosemicarbazide $(0.92 \mathrm{~g}, 10 \mathrm{mmol})$ in $\mathrm{EtOH}(20 \mathrm{~mL})$, a catalytic amount of triethylamine $(1 \mathrm{~mL}) \mathrm{was}$ added, then heated under reflux for $6 \mathrm{~h}$. The resulting solid was collected, washed with EtOH and recrystallized from acetic acid to give pure 5 as white solid $(74 \%) ; \mathrm{mp} 179-181^{\circ} \mathrm{C}$; IR (KBr): $v 3426$, 3212, $3175\left(\mathrm{NH}_{2}\right.$ and NH), $1569(\mathrm{C}=\mathrm{N}) \mathrm{cm}^{-1} ;{ }^{1} \mathrm{H}-\mathrm{NMR}\left(\mathrm{DMSO}-d_{6}\right): \delta 2.35\left(\mathrm{~s}, 3 \mathrm{H}, \mathrm{CH}_{3}\right), 3.17(\mathrm{dd}, 1 \mathrm{H}$, $\left.\mathrm{H}_{\mathrm{A}}, J=17.2,6.3 \mathrm{~Hz}\right), 3.46\left(\mathrm{dd}, 1 \mathrm{H}, \mathrm{H}_{\mathrm{B}}, J=17.2,12.1 \mathrm{~Hz}\right), 5.87\left(\mathrm{dd}, 1 \mathrm{H}, \mathrm{H}_{\mathrm{X}}, J=12.2,6.3 \mathrm{~Hz}\right), 7.02-8.34$ (m, 8H, Ar-H), 8.72 (s, 1H, Indole- $\left.\mathrm{H}_{2}\right), 11.54$ (br s, 2H, $\left.\mathrm{NH}_{2}\right), 12.10$ (br s, 1H, NH); MS m/z (\%): 334 $\left(\mathrm{M}^{+}, 11\right), 228$ (43), 196 (48), 109 (100), 79 (29), 52 (27). Anal. Calcd. for $\mathrm{C}_{19} \mathrm{H}_{18} \mathrm{~N}_{4} \mathrm{~S}$ (334.44): C, 68.23; H, $5.42 ; \mathrm{N}, 16.75$. Found C, 68.18; H, 5.35; N, 16.59 .

\subsubsection{Synthesis of Thiones $(7 \mathbf{a}, \mathbf{b})$}

A mixture of chalcones $\mathbf{3 a}, \mathbf{b}$ (10 mmol) and 6-amino-2-thioxo-2,3,4-trihydro- $1 \mathrm{H}$ - pyrimidin-4-one (6) $(1.43 \mathrm{~g}, 10 \mathrm{mmol})$ in glacial acetic acid $(30 \mathrm{~mL})$ was heated under reflux for $5 \mathrm{~h}$. After cooling, the reaction mixture was poured into an ice/conc $\mathrm{HCl}$ mixture and the formed solid was collected and recrystallized from DMF to give thiones $\mathbf{7 a}, \mathbf{b}$, respectively.

7-(1H-Indol-3-yl)-2-thioxo-5-(p-tolyl)-2,3-dihydropyrido[2,3-d]pyrimidin-4(1H)-one (7a). Yellow crystals, 72\%, mp 265-267 ${ }^{\circ} \mathrm{C}$; IR (KBr): $v$ 3442, 3392, 3271 (3NH), $1675(\mathrm{C}=\mathrm{O}), 1595$ (C=N) cm ${ }^{-1} ;{ }^{1} \mathrm{H}-\mathrm{NMR}$ $\left(\mathrm{DMSO}-d_{6}\right): \delta 2.44\left(\mathrm{~s}, 3 \mathrm{H}, \mathrm{CH}_{3}\right), 4.69$ (br s, 1H, NH), 7.15-8.28 (m, 9H, Ar-H and pyridine-H), $8.69(\mathrm{~s}$, $1 \mathrm{H}$, indole- $\mathrm{H}_{2}$ ), 11.46 (br s, 1H, NH), 11.88 (br s, 1H, NH); MS, $m / z$ (\%) $384\left(\mathrm{M}^{+}, 23\right), 249$ (68), 192 (100), 119 (26), 73 (83). Anal. Calcd. for $\mathrm{C}_{22} \mathrm{H}_{16} \mathrm{~N}_{4} \mathrm{OS}$ (384.45): C, 68.73; H, 4.19; N, 14.57. Found: C, 68.59; $\mathrm{H}$, $4.06 ; \mathrm{N}, 14.43$.

5-(4-Chlorophenyl)-7-(1H-indol-3-yl)-2-thioxo-2,3-dihydropyrido[2,3-d]pyrimidin-4(1H)-one (7b). Yellow crystals, $76 \%$, mp $276-278{ }^{\circ} \mathrm{C}$; IR (KBr): $v$ 3463, 3368, $3163(3 \mathrm{NH}), 1678(\mathrm{C}=\mathrm{O}), 1595(\mathrm{C}=\mathrm{N}) \mathrm{cm}^{-1}$; 
${ }^{1} \mathrm{H}-\mathrm{NMR}\left(\mathrm{DMSO}-d_{6}\right): \delta 2.44\left(\mathrm{~s}, 3 \mathrm{H}, \mathrm{CH}_{3}\right), 4.70(\mathrm{br} \mathrm{s}, 1 \mathrm{H}, \mathrm{NH}), 7.10-8.32(\mathrm{~m}, 9 \mathrm{H}, \mathrm{Ar}-\mathrm{H}$ and pyridine-H), $8.72\left(\mathrm{~s}, 1 \mathrm{H}\right.$, indole- $\left.\mathrm{H}_{2}\right), 11.48$ (br s, $\left.1 \mathrm{H}, \mathrm{NH}\right), 12.04(\mathrm{br} \mathrm{s}, 1 \mathrm{H}, \mathrm{NH}) ; \mathrm{MS}, m / z(\%) 404\left(\mathrm{M}^{+}, 3\right), 278(100)$, 151 (66), 105 (18), 57 (23). Anal. Calcd. for $\mathrm{C}_{21} \mathrm{H}_{13} \mathrm{ClN}_{4} \mathrm{OS}$ (404.87): C, 62.30; H, 3.24; N, 13.84. Found: $\mathrm{C}$, 62.18; H, 3.20; N, 13.65 .

3.1.3. Synthesis of 2-(3-(1H-Indol-3-yl)-5-(p-tolyl)-4,5-dihydro-1H-pyrazol-1-yl)-4-substituted-5-(aryl diazenyl)thiazole (12a-e)

A mixture of 3-(1H-indol-3-yl)-5-(p-tolyl)-4,5-dihydro- $1 H$-pyrazole-1-carbothioamide (5) (0.334 g, $1 \mathrm{mmol})$ and the appropriate hydrazonoyl halides $8 \mathbf{a}-\mathbf{e}(1 \mathrm{mmol})$ in dioxane $(20 \mathrm{~mL})$ containing TEA $(0.5 \mathrm{~mL})$ was refluxed for $4 \mathrm{~h}$ (monitored by TLC), allowed to cool and the solid formed was collected, washed with $\mathrm{EtOH}$, dried, and recrystallized from DMF to give 12a-e.

2-(3-(1H-Indol-3-yl)-5-(p-tolyl)-4,5-dihydro-1H-pyrazol-1-yl)-4-methyl-5-(phenyldiazenyl)thiazole (12a). Red solid, (78\% yield); mp 210-212 ${ }^{\circ} \mathrm{C}$; IR (KBr): $v 3409(\mathrm{NH}), 1642,1593(\mathrm{C}=\mathrm{N}) \mathrm{cm}^{-1} ;{ }^{1} \mathrm{H}-\mathrm{NMR}$ (DMSO- $\left.d_{6}\right): \delta 2.35\left(\mathrm{~s}, 3 \mathrm{H}, \mathrm{CH}_{3}\right), 2.54\left(\mathrm{~s}, 3 \mathrm{H}, \mathrm{CH}_{3}\right), 3.24\left(\mathrm{dd}, 1 \mathrm{H}, \mathrm{H}_{\mathrm{A}}, J=17.2,6.3 \mathrm{~Hz}\right), 3.40\left(\mathrm{dd}, 1 \mathrm{H}, \mathrm{H}_{\mathrm{B}}\right.$, $J=17.2,12.1 \mathrm{~Hz}), 5.88\left(\mathrm{dd}, 1 \mathrm{H}, \mathrm{H}_{\mathrm{X}}, J=12.2,6.3 \mathrm{~Hz}\right), 7.17-8.34(\mathrm{~m}, 13 \mathrm{H}, \mathrm{Ar}-\mathrm{H}), 8.72\left(\mathrm{~s}, 1 \mathrm{H}\right.$, indole- $\left.\mathrm{H}_{2}\right)$, 12.10 (br s, $1 \mathrm{H}, \mathrm{NH}$ ); ${ }^{13} \mathrm{C}-\mathrm{NMR}$ (DMSO- $d_{6}$ ): $\delta 12.2,21.0,36.3,68.0,109.5,111.1,114.8,117.1,119.8,121.7$, $128.8,130.2,130.5,131.4,133.2,138.2,136.1,147.8,150.1,154.0,161.2 ; \mathrm{MS}, m / z(\%) 476\left(\mathrm{M}^{+}, 61\right), 349$ (19), 249 (44), 152 (50), 29 (100). Anal. Calcd. for $\mathrm{C}_{28} \mathrm{H}_{24} \mathrm{~N}_{6} \mathrm{~S}$ (476.60): C, 70.56; H, 5.08; N, 17.63; found: C, $70.47 ; \mathrm{H}, 5.01 ; \mathrm{N}, 17.53$.

2-(3-(1H-Indol-3-yl)-5-(p-tolyl)-4,5-dihydro-1H-pyrazol-1-yl)-4-methyl-5-(p-tolyldiazenyl)thiazole (12b). Red solid, (72\% yield); mp 193-195 ${ }^{\circ} \mathrm{C}$; IR (KBr): $v 3403(\mathrm{NH}), 1642,1590(\mathrm{C}=\mathrm{N}) \mathrm{cm}^{-1} ;{ }^{1} \mathrm{H}-\mathrm{NMR}$ (DMSO- $\left.d_{6}\right): \delta 2.18\left(\mathrm{~s}, 3 \mathrm{H}, \mathrm{CH}_{3}\right), 2.35\left(\mathrm{~s}, 3 \mathrm{H}, \mathrm{CH}_{3}\right), 2.57\left(\mathrm{~s}, 3 \mathrm{H}, \mathrm{CH}_{3}\right), 3.05\left(\mathrm{dd}, 1 \mathrm{H}, \mathrm{H}_{\mathrm{A}}, J=17.2,6.3 \mathrm{~Hz}\right)$, $3.57\left(\mathrm{dd}, 1 \mathrm{H}, \mathrm{H}_{\mathrm{B}}, J=17.2,12.1 \mathrm{~Hz}\right), 5.84\left(\mathrm{dd}, 1 \mathrm{H}, \mathrm{H}_{\mathrm{X}}, J=12.2,6.3 \mathrm{~Hz}\right), 7.12-8.34(\mathrm{~m}, 12 \mathrm{H}, \mathrm{Ar}-\mathrm{H}), 8.71(\mathrm{~s}$, $1 \mathrm{H}$, indole- $\mathrm{H}_{2}$ ), 12.09 (br s, 1H, NH); MS, $m / z$ (\%) $490\left(\mathrm{M}^{+}, 2\right), 368$ (100), 255 (26), 147 (40), 105 (37), 91 (41), 55 (40). Anal. Calcd. for $\mathrm{C}_{29} \mathrm{H}_{26} \mathrm{~N}_{6} \mathrm{~S}$ (490.62): C, 70.99; H, 5.34; N, 17.13; found: C, 70.76; $\mathrm{H}, 5.22$; $\mathrm{N}, 17.05$.

2-(3-(1H-Indol-3-yl)-5-(p-tolyl)-4,5-dihydro-1H-pyrazol-1-yl)-5-((4-chlorophenyl)diazenyl)-4-methyl-thiazole (12c). Red solid, (75\% yield); mp 206-208 ${ }^{\circ} \mathrm{C}$; IR (KBr): $v 3403(\mathrm{NH}), 1642,1590(\mathrm{C}=\mathrm{N}) \mathrm{cm}^{-1} ;{ }^{1} \mathrm{H}-\mathrm{NMR}$ (DMSO- $\left.d_{6}\right): \delta 2.35\left(\mathrm{~s}, 3 \mathrm{H}, \mathrm{CH}_{3}\right), 2.58\left(\mathrm{~s}, 3 \mathrm{H}, \mathrm{CH}_{3}\right), 3.28\left(\mathrm{dd}, 1 \mathrm{H}, \mathrm{H}_{\mathrm{A}}, J=17.2,6.3 \mathrm{~Hz}\right), 3.57\left(\mathrm{dd}, 1 \mathrm{H}, \mathrm{H}_{\mathrm{B}}\right.$, $J=17.2,12.1 \mathrm{~Hz}), 5.80\left(\mathrm{dd}, 1 \mathrm{H}, \mathrm{H}_{\mathrm{X}}, J=12.2,6.3 \mathrm{~Hz}\right), 7.17-8.34(\mathrm{~m}, 12 \mathrm{H}, \mathrm{Ar}-\mathrm{H}), 8.72\left(\mathrm{~s}, 1 \mathrm{H}\right.$, indole- $\left.\mathrm{H}_{2}\right)$, 12.09 (br s, 1H, NH); MS, m/z (\%) $511\left(\mathrm{M}^{+}, 34\right), 452$ (69), 262 (86), 189 (100), 136 (37), 95 (48), 43 (50). Anal. Calcd. for $\mathrm{C}_{28} \mathrm{H}_{23} \mathrm{ClN}_{6} \mathrm{~S}$ (511.04): $\mathrm{C}, 65.81 ; \mathrm{H}, 4.54 ; \mathrm{N}, 16.44$; found: $\mathrm{C}, 65.65 ; \mathrm{H}, 4.37 ; \mathrm{N}, 16.30$.

2-(3-(1H-Indol-3-yl)-5-(p-tolyl)-4,5-dihydro-1H-pyrazol-1-yl)-5-((4-bromophenyl)diazenyl)-4-methyl-thiazole (12d). Red solid, (78\% yield); mp 186-188 ${ }^{\circ} \mathrm{C}$; IR (KBr): $v 3409$ (NH), 1641, $1586(\mathrm{C}=\mathrm{N}) \mathrm{cm}^{-1}$; ${ }^{1} \mathrm{H}-\mathrm{NMR}$ (DMSO- $\left.d_{6}\right): \delta 2.35\left(\mathrm{~s}, 3 \mathrm{H}, \mathrm{CH}_{3}\right), 2.58\left(\mathrm{~s}, 3 \mathrm{H}, \mathrm{CH}_{3}\right), 3.23\left(\mathrm{dd}, 1 \mathrm{H}, \mathrm{H}_{\mathrm{A}}, J=17.2,6.3 \mathrm{~Hz}\right), 3.56\left(\mathrm{dd}, 1 \mathrm{H}, \mathrm{H}_{\mathrm{B}}\right.$, $J=17.2,12.1 \mathrm{~Hz}), 5.78\left(\mathrm{dd}, 1 \mathrm{H}, \mathrm{H}_{\mathrm{X}}, J=12.2,6.3 \mathrm{~Hz}\right), 7.17-8.34(\mathrm{~m}, 12 \mathrm{H}, \mathrm{Ar}-\mathrm{H}), 8.71\left(\mathrm{~s}, 1 \mathrm{H}\right.$, indole- $\left.\mathrm{H}_{2}\right)$, 12.09 (br s, 1H, NH); MS, m/z (\%) $556\left(\mathrm{M}^{+}, 12\right), 370$ (37), 248 (60), 235 (100), 91 (48), 55 (36). Anal. Calcd. for $\mathrm{C}_{28} \mathrm{H}_{23} \mathrm{BrN}_{6} \mathrm{~S}$ (555.49): C, 60.54; $\mathrm{H}, 4.17 ; \mathrm{N}, 15.13$; found: $\mathrm{C}, 60.48 ; \mathrm{H}, 4.11 ; \mathrm{N}, 15.06$.

2-(3-(1H-Indol-3-yl)-5-(p-tolyl)-4,5-dihydro-1H-pyrazol-1-yl)-4-phenyl-5-(phenyldiazenyl)thiazole (12e). Red solid, (72\% yield); mp 232-234 ${ }^{\circ} \mathrm{C}$; IR (KBr): $v 3404(\mathrm{NH}), 1640,1591(\mathrm{C}=\mathrm{N}) \mathrm{cm}^{-1} ;{ }^{1} \mathrm{H}-\mathrm{NMR}$ (DMSO- $\left.d_{6}\right): \delta 2.35\left(\mathrm{~s}, 3 \mathrm{H}, \mathrm{CH}_{3}\right), 3.25\left(\mathrm{dd}, 1 \mathrm{H}, \mathrm{H}_{\mathrm{A}}, J=17.2,6.3 \mathrm{~Hz}\right), 3.48\left(\mathrm{dd}, 1 \mathrm{H}, \mathrm{H}_{\mathrm{B}}, J=17.2,12.1 \mathrm{~Hz}\right)$, $5.84\left(\mathrm{dd}, 1 \mathrm{H}, \mathrm{H}_{\mathrm{X}}, J=12.2,6.3 \mathrm{~Hz}\right), 7.17-8.34(\mathrm{~m}, 18 \mathrm{H}, \mathrm{Ar}-\mathrm{H}), 8.72\left(\mathrm{~s}, 1 \mathrm{H}\right.$, indole- $\left.\mathrm{H}_{2}\right), 12.08(\mathrm{br} \mathrm{s}, 1 \mathrm{H}$, $\mathrm{NH}$ ); ${ }^{13} \mathrm{C}-\mathrm{NMR}$ (DMSO- $d_{6}$ ): $\delta 21.0,35.8,68.0,106.0,109.5,110.9,117.3,119.8,121.4,121.2,125.4,128.1$, 128.4, 129.5, 130.1, 130.4, 131.4, 133.0, 133.4, 135.1, 136.0, 136.4, 147.8, 150.6, 154.6, 168.1; MS, $m / z$ (\%) $538\left(\mathrm{M}^{+}, 9\right), 451(4), 432(43), 326(62), 225$ (100), 77 (64). Anal. Calcd for $\mathrm{C}_{33} \mathrm{H}_{26} \mathrm{~N}_{6} \mathrm{~S}$ (538.66): $\mathrm{C}, 73.58$; $\mathrm{H}, 4.87$; N, 15.60; found: C, 73.49; H, 4.79; N, 15.47 . 


\subsubsection{Alternate Synthesis of $\mathbf{1 2 e}$}

Synthesis of 2-(3-(1H-indol-3-yl)-5-( $p$-tolyl)-4,5-dihydro-1H-pyrazol-1-yl)-4-phenylthiazole (15e). A mixture of 3-(1H-indol-3-yl)-5-( $p$-tolyl)-4,5-dihydro-1H-pyrazole-1-carbothioamide (5) (0.668 g, $2 \mathrm{mmol})$ and phenacyl bromide (14) $(0.398 \mathrm{~g}, 2 \mathrm{mmol})$ in absolute EtOH $(30 \mathrm{~mL})$ was refluxed for $4 \mathrm{~h}$. The product started to separate out during the course of reaction. The crystalline solid was filtered, washed with water, dried, and recrystallized from EtOH to give pure thiazole 15e as yellow crystals in 77\% yield; mp 177-179 ${ }^{\circ} \mathrm{C}$; IR (KBr) $v 3389(\mathrm{CH}), 1616(\mathrm{C}=\mathrm{N}) \mathrm{cm}^{-1} ;{ }^{1} \mathrm{H}-\mathrm{NMR}\left(300 \mathrm{MHz}, \mathrm{DMSO}-d_{6}\right): \delta$ $2.34\left(\mathrm{~s}, 3 \mathrm{H}, \mathrm{CH}_{3}\right), 3.17\left(\mathrm{dd}, 1 \mathrm{H}, \mathrm{H}_{\mathrm{A}}, J=17.6,6.1 \mathrm{~Hz}\right), 4.19\left(\mathrm{dd}, 1 \mathrm{H}, \mathrm{H}_{\mathrm{B}}, J=17.6,12.2 \mathrm{~Hz}\right), 5.80(\mathrm{dd}, 1 \mathrm{H}$, $\left.\mathrm{H}_{\mathrm{X}}, \mathrm{J}=12.4,6.1 \mathrm{~Hz}\right), 6.85$ (s, 1H, thiazole-H5), 7.25-8.32 (m, 13H, Ar-H ), $8.72\left(\mathrm{~s}, 1 \mathrm{H}\right.$, indole- $\left.\mathrm{H}_{2}\right), 12.10$ (br s, 1H, NH); MS, m/z (\%) $434\left(\mathrm{M}^{+}, 2\right), 324$ (37), 225 (100), 183 (68), 157 (74), 72 (58). Anal. Calcd. for $\mathrm{C}_{27} \mathrm{H}_{22} \mathrm{~N}_{4} \mathrm{~S}$ (434.56): C, 74.63; H, 5.10; N, 12.89; found: C, 74.59; H, 5.07; N, 12.69 .

Coupling of Thiazole 15e with Benzenediazonium Chloride

To a solution of $15 \mathbf{e}(0.434 \mathrm{~g}, 1 \mathrm{mmol})$ in $\mathrm{EtOH}(20 \mathrm{~mL})$ was added sodium acetate trihydrate $(0.138 \mathrm{~g}, 1 \mathrm{mmol})$, and the mixture was cooled to $0-5{ }^{\circ} \mathrm{C}$ in an ice bath. To the resulting cold solution was added portionwise a cold solution of benzenediazonium chloride (prepared by diazotizing aniline $(1 \mathrm{mmol})$ dissolved in hydrochloric acid $(6 \mathrm{M}, 1 \mathrm{~mL})$ with a solution of sodium nitrite $(0.07 \mathrm{~g}, 1 \mathrm{mmol})$ in water $(2 \mathrm{~mL}))$. After complete addition of the diazonium salt, the reaction mixture was stirred for a further $30 \mathrm{~min}$ in an ice bath. The solid that separated was filtered off, washed with water, and finally recrystallized from DMF to give a product that proved identical in all respects (mp, mixed mp and IR spectra) with compound 12e obtained from reaction of 5 with 8 e in $70 \%$ yield.

\subsubsection{General Procedure for the Reaction of Hydrazonoyl Halides $\mathbf{8}$ with Thiones 7a,b}

To a solution of thione $7 \mathbf{a}$ or $\mathbf{7 b}(1 \mathrm{mmol})$ and the appropriate hydrazonoyl halides $\mathbf{8}(1 \mathrm{mmol})$ in dioxane $(20 \mathrm{~mL})$ was added TEA $(0.14 \mathrm{~mL}, 1 \mathrm{mmol})$. The reaction mixture was refluxed until all of the starting materials had disappeared ( $8-12 \mathrm{~h}$, monitored by TLC). The solvent was evaporated and the residue was triturated with $\mathrm{MeOH}$. The solid formed was collected and recrystallized from the appropriate solvent to give products 19a-1. The products $19 \mathrm{a}-\mathbf{1}$ together with their physical constants are listed below.

9-Acetyl-2-(1H-indol-3-yl)-7-phenyl-4-(p-tolyl)pyrido[3,2-e][1,2,4]triazolo[4,3-a]pyrimidin-5 (7H)-one (19a). Yellow solid, (80\% yield), mp 253-255 ${ }^{\circ} \mathrm{C}$; IR (KBr): $v 3435(\mathrm{NH}), 1706,1633(2 \mathrm{C}=\mathrm{O}), 1590(\mathrm{C}=\mathrm{N}) \mathrm{cm}^{-1}$; ${ }^{1} \mathrm{H}-\mathrm{NMR}\left(\mathrm{DMSO}-d_{6}\right): \delta 2.35\left(\mathrm{~s}, 3 \mathrm{H}, \mathrm{CH}_{3}\right), 2.49\left(\mathrm{~s}, 3 \mathrm{H}, \mathrm{CH}_{3}\right), 7.30-8.38(\mathrm{~m}, 14 \mathrm{H}, \mathrm{Ar}-\mathrm{H}$ and pyridine-H), 8.72 (s, $1 \mathrm{H}$, indole- $\mathrm{H}_{2}$ ), 12.02 (br s, $\left.1 \mathrm{H}, \mathrm{NH}\right) ;{ }^{13} \mathrm{C}-\mathrm{NMR}\left(\mathrm{DMSO}-d_{6}\right) \delta: 21.0,25.5,109.4,113.6,115.8$, 119.0, 120.9, 121.0, 123.9, 126.2, 127.1, 129.2, 129.6, 131.4, 131.8, 133.8, 136.4, 140.9, 146.2, 148.4, 161.0, 163.9, 167.1, 180.6; MS, m/z (\%) $510\left(\mathrm{M}^{+}, 36\right), 407$ (23), 334 (22), 233 (27), 105 (100), 77 (22). Anal. Calcd. for $\mathrm{C}_{31} \mathrm{H}_{22} \mathrm{~N}_{6} \mathrm{O}_{2}$ (510.55): C, 72.93; $\mathrm{H}, 4.34 ; \mathrm{N}, 16.46$. Found: $\mathrm{C}, 72.76 ; \mathrm{H}, 4.32 ; \mathrm{N}, 16.28$.

9-Acetyl-2-(1H-indol-3-yl)-4,7-di-p-tolylpyrido[3,2-e][1,2,4]triazolo[4,3-a]pyrimidin-5(7H)-one (19b). Yellow solid, (76\% yield), mp 242-244 ${ }^{\circ} \mathrm{C}$; IR (KBr): v $3421(\mathrm{NH}), 1707,1642(2 \mathrm{C}=\mathrm{O}), 1589(\mathrm{C}=\mathrm{N}) \mathrm{cm}^{-1}$; ${ }^{1} \mathrm{H}-\mathrm{NMR}\left(\mathrm{DMSO}-d_{6}\right): \delta 2.23\left(\mathrm{~s}, 3 \mathrm{H}, \mathrm{CH}_{3}\right), 2.34\left(\mathrm{~s}, 3 \mathrm{H}, \mathrm{CH}_{3}\right), 2.48\left(\mathrm{~s}, 3 \mathrm{H}, \mathrm{CH}_{3}\right), 7.07-8.28(\mathrm{~m}, 13 \mathrm{H}, \mathrm{Ar}-\mathrm{H}$ and pyridine-H), 8.70 (s, 1H, indole- $\left.\mathrm{H}_{2}\right), 12.03$ (br s, 1H, NH); MS, $m / z$ (\%) $524\left(\mathrm{M}^{+}, 22\right), 509$ (100), 381 (32), 231 (96), 173 (79), 55 (63). Anal. Calcd. for $\mathrm{C}_{32} \mathrm{H}_{24} \mathrm{~N}_{6} \mathrm{O}_{2}$ (524.57): C, 73.27; H, 4.61; N, 16.02. Found: C, 73.12; H, 4.48; N, 15.93 .

9-Acetyl-7-(4-chlorophenyl)-2-(1H-indol-3-yl)-4-(p-tolyl)pyrido[3,2-e][1,2,4]triazolo[4,3-a]pyrimidin-5(7H)-one (19c). Yellow solid, (83\% yield), mp 264-265 ${ }^{\circ} \mathrm{C}$; IR (KBr): v $3386(\mathrm{NH}), 1710,1644(2 \mathrm{C}=\mathrm{O}), 1589(\mathrm{C}=\mathrm{N})$ $\mathrm{cm}^{-1} ;{ }^{1} \mathrm{H}-\mathrm{NMR}\left(\mathrm{DMSO}-d_{6}\right): \delta 2.35\left(\mathrm{~s}, 3 \mathrm{H}, \mathrm{CH}_{3}\right), 2.44\left(\mathrm{~s}, 3 \mathrm{H}, \mathrm{CH}_{3}\right), 7.09-8.34(\mathrm{~m}, 13 \mathrm{H}, \mathrm{Ar}-\mathrm{H}$ and pyridine-H), 8.71 (s, 1H, indole- $\mathrm{H}_{2}$ ), 12.09 (br s, 1H, NH); MS, $m / z$ (\%) $545\left(\mathrm{M}^{+}, 3\right), 490$ (24), 258 (30), 152 (47), 29 (100). Anal. Calcd. for $\mathrm{C}_{31} \mathrm{H}_{21} \mathrm{ClN}_{6} \mathrm{O}_{2}$ (544.99): C, 68.32; H, 3.88; N, 15.42. Found: C, 68.20; $\mathrm{H}, 3.69 ; \mathrm{N}, 15.31$. 
9-Acetyl-7-(4-bromophenyl)-2-(1H-indol-3-yl)-4-(p-tolyl)pyrido[3,2-e][1,2,4]triazolo[4,3-a]pyrimidin-5(7H)-one (19d). Yellow solid, (78\% yield), mp 254-256 ${ }^{\circ} \mathrm{C}$; IR (KBr): $v 3389(\mathrm{NH}), 1711,1643(2 \mathrm{C}=\mathrm{O}), 1583$ $(\mathrm{C}=\mathrm{N}) \mathrm{cm}^{-1} ;{ }^{1} \mathrm{H}-\mathrm{NMR}\left(\mathrm{DMSO}-d_{6}\right): \delta 2.35\left(\mathrm{~s}, 3 \mathrm{H}, \mathrm{CH}_{3}\right), 2.45\left(\mathrm{~s}, 3 \mathrm{H}, \mathrm{CH}_{3}\right), 7.08-8.34(\mathrm{~m}, 13 \mathrm{H}, \mathrm{Ar}-\mathrm{H}$ and pyridine-H), $8.73\left(\mathrm{~s}, 1 \mathrm{H}\right.$, indole- $\left.\mathrm{H}_{2}\right), 12.10$ (br s, $\left.1 \mathrm{H}, \mathrm{NH}\right) ; \mathrm{MS}, \mathrm{m} / z(\%) 589\left(\mathrm{M}^{+}, 4\right), 397$ (41), 279 (100), 236 (52), 193 (52), 43 (40). Anal. Calcd. for $\mathrm{C}_{31} \mathrm{H}_{21} \mathrm{BrN}_{6} \mathrm{O}_{2}$ (589.44): $\mathrm{C}, 63.17 ; \mathrm{H}, 3.59 ; \mathrm{N}, 14.26$. Found: C, 63.09; H, 3.42; N, 14.17 .

Ethyl2-(1H-Indol-3-yl)-5-oxo-7-phenyl-4-(p-tolyl)-5,7-dihydropyrido[3,2-e][1,2,4]triazolo[4,3-a]-pyrimidine-9carboxylate (19e). Yellow solid, (75\% yield), mp 212-214 ${ }^{\circ} \mathrm{C}$; IR (KBr): $v 3342(\mathrm{NH}), 1718,1644(2 \mathrm{C}=\mathrm{O})$, $1579(\mathrm{C}=\mathrm{N}) \mathrm{cm}^{-1} ;{ }^{1} \mathrm{H}-\mathrm{NMR}\left(\mathrm{DMSO}-d_{6}\right): \delta 1.29\left(\mathrm{t}, J=7.1 \mathrm{~Hz}, 3 \mathrm{H}, \mathrm{CH}_{3}\right), 2.34\left(\mathrm{~s}, 3 \mathrm{H}, \mathrm{CH}_{3}\right), 4.29(\mathrm{q}, J=7.1$ $\left.\mathrm{Hz}, 2 \mathrm{H}, \mathrm{CH}_{2}\right), 7.13-8.30(\mathrm{~m}, 14 \mathrm{H}, \mathrm{Ar}-\mathrm{H}$ and pyridine- $\mathrm{H}), 8.73\left(\mathrm{~s}, 1 \mathrm{H}\right.$, indole- $\left.\mathrm{H}_{2}\right), 12.12(\mathrm{br} \mathrm{s}, 1 \mathrm{H}, \mathrm{NH})$; MS, $m / z(\%) 540\left(\mathrm{M}^{+}, 2\right), 521$ (16), 361 (13), 270 (69),167 (38), 91 (100). Anal. Calcd. for $\mathrm{C}_{32} \mathrm{H}_{24} \mathrm{~N}_{6} \mathrm{O}_{3}$ (540.57): C, 71.10; H, 4.47; N, 15.55. Found: C, 71.07; H, 4.39; N, 15.37.

Ethyl2-(1H-Indol-3-yl)-5-oxo-4,7-di-p-tolyl-5,7-dihydropyrido[3,2-e][1,2,4]triazolo[4,3-a]pyrimidine-9-carboxylate (19f). Yellow solid, (77\% yield), mp 238-240 ${ }^{\circ} \mathrm{C}$; IR (KBr): $v 3348(\mathrm{NH}), 1746,1673(2 \mathrm{C}=\mathrm{O}), 1576(\mathrm{C}=\mathrm{N})$ $\mathrm{cm}^{-1} ;{ }^{1} \mathrm{H}-\mathrm{NMR}$ (DMSO- $\left.d_{6}\right): \delta 1.30\left(\mathrm{t}, J=7.1 \mathrm{~Hz}, 3 \mathrm{H}, \mathrm{CH}_{3}\right), 2.23\left(\mathrm{~s}, 3 \mathrm{H}, \mathrm{CH}_{3}\right), 2.35\left(\mathrm{~s}, 3 \mathrm{H}, \mathrm{CH}_{3}\right), 4.26$ $\left(\mathrm{q}, J=7.1 \mathrm{~Hz}, 2 \mathrm{H}, \mathrm{CH}_{2}\right), 7.08-8.32(\mathrm{~m}, 13 \mathrm{H}, \mathrm{Ar}-\mathrm{H}$ and pyridine- $\mathrm{H}), 8.72\left(\mathrm{~s}, 1 \mathrm{H}\right.$, indole- $\left.\mathrm{H}_{2}\right), 12.09$ (br s, 1H, NH); MS, $m / z$ (\%) $554\left(\mathrm{M}^{+}, 4\right), 522$ (24), 431 (100), 326 (88), 282 (25), 91 (10). Anal. Calcd. for $\mathrm{C}_{33} \mathrm{H}_{26} \mathrm{~N}_{6} \mathrm{O}_{3}$ (554.60): C, 71.47; H, 4.73; N, 15.15. Found: C, 71.38; H, 4.70; N, 15.04 .

Ethyl2-(1H-Indol-3-yl)-7-(4-methoxyphenyl)-5-oxo-4-(p-tolyl)-5,7-dihydropyrido[3,2-e][1,2,4]triazolo-[4,3-a] pyrimidine-9-carboxylate (19g). Yellow solid, (70\% yield), mp 193-195 ${ }^{\circ} \mathrm{C}$; IR (KBr): $v 3390(\mathrm{NH}), 1740$, $1674(2 \mathrm{C}=\mathrm{O}), 1578(\mathrm{C}=\mathrm{N}) \mathrm{cm}^{-1} ;{ }^{1} \mathrm{H}-\mathrm{NMR}\left(\mathrm{DMSO}-d_{6}\right): \delta 1.32\left(\mathrm{t}, J=7.1 \mathrm{~Hz}, 3 \mathrm{H}, \mathrm{CH}_{3}\right), 2.35\left(\mathrm{~s}, 3 \mathrm{H}, \mathrm{CH}_{3}\right)$, $3.82\left(\mathrm{~s}, 3 \mathrm{H}, \mathrm{OCH}_{3}\right), 4.34\left(\mathrm{q}, J=7.1 \mathrm{~Hz}, 2 \mathrm{H}, \mathrm{CH}_{2}\right), 7.03-8.34(\mathrm{~m}, 13 \mathrm{H}, \mathrm{Ar}-\mathrm{H}$ and pyridine-H), $8.72(\mathrm{~s}, 1 \mathrm{H}$, indole- $\left.\mathrm{H}_{2}\right), 12.10$ (br s, $\left.1 \mathrm{H}, \mathrm{NH}\right) ; \mathrm{MS}, m / z(\%) 570\left(\mathrm{M}^{+}, 10\right), 354$ (52), 311 (62), 267 (85), 72 (54), 59 (100). Anal. Calcd. for $\mathrm{C}_{33} \mathrm{H}_{26} \mathrm{~N}_{6} \mathrm{O}_{4}$ (570.60): $\mathrm{C}, 69.46 ; \mathrm{H}, 4.59 ; \mathrm{N}, 14.73$. Found: $\mathrm{C}, 69.39 ; \mathrm{H}, 4.48 ; \mathrm{N}, 14.59$.

Ethyl7-(4-Chlorophenyl)-2-(1H-indol-3-yl)-5-oxo-4-(p-tolyl)-5,7-dihydropyrido[3,2-e][1,2,4]triazolo-[4,3-a] pyrimidine-9-carboxylate (19h). Yellow solid, (78\% yield), mp 243-245 ${ }^{\circ} \mathrm{C}$; IR (KBr): v $3383(\mathrm{NH}), 1742$, $1675(2 \mathrm{C}=\mathrm{O}), 1577(\mathrm{C}=\mathrm{N}) \mathrm{cm}^{-1},{ }^{1} \mathrm{H}-\mathrm{NMR}\left(\mathrm{DMSO}-d_{6}\right): \delta 1.31\left(\mathrm{t}, J=7.1 \mathrm{~Hz}, 3 \mathrm{H}, \mathrm{CH}_{3}\right), 2.35\left(\mathrm{~s}, 3 \mathrm{H}, \mathrm{CH}_{3}\right)$, $4.37\left(\mathrm{q}, J=7.1 \mathrm{~Hz}, 2 \mathrm{H}, \mathrm{CH}_{2}\right), 7.07-8.34(\mathrm{~m}, 13 \mathrm{H}, \mathrm{Ar}-\mathrm{H}$ and pyridine- $\mathrm{H}), 8.72\left(\mathrm{~s}, 1 \mathrm{H}\right.$, indole- $\left.\mathrm{H}_{2}\right), 12.09 \mathrm{(br}$ s, 1H, NH); MS, m/z (\%) 575 ( $\left.\mathrm{M}^{+}, 17\right), 352$ (12), 293 (29), 126 (23), 72 (59), 59 (100). Anal. Calcd. for $\mathrm{C}_{32} \mathrm{H}_{23} \mathrm{ClN}_{6} \mathrm{O}_{3}$ (575.02): $\mathrm{C}, 66.84 ; \mathrm{H}, 4.03 ; \mathrm{N}, 14.62$. Found: $\mathrm{C}, 66.69 ; \mathrm{H}, 4.01 ; \mathrm{N}, 14.47$.

2-(1H-Indol-3-yl)-5-oxo-N,7-diphenyl-4-(p-tolyl)-5,7-dihydropyrido[3,2-e][1,2,4]triazolo[4,3-a]-pyrimidine-9carboxamide (19i). Yellow solid, (82\% yield), $\mathrm{mp} 268-270{ }^{\circ} \mathrm{C}$; IR (KBr): $v 3385,3213(2 \mathrm{NH}), 1679,1641$ $(2 \mathrm{C}=\mathrm{O}), 1598(\mathrm{C}=\mathrm{N}) \mathrm{cm}^{-1} ;{ }^{1} \mathrm{H}-\mathrm{NMR}\left(\mathrm{DMSO}-d_{6}\right): \delta 2.35\left(\mathrm{~s}, 3 \mathrm{H}, \mathrm{CH}_{3}\right), 7.02-8.34(\mathrm{~m}, 19 \mathrm{H}, \mathrm{Ar}-\mathrm{H}$ and pyridine-H), $8.72\left(\mathrm{~s}, 1 \mathrm{H}\right.$, indole- $\left.\mathrm{H}_{2}\right), 10.92$ (br s, $\left.1 \mathrm{H}, \mathrm{NH}\right), 12.10$ (br s, $\left.1 \mathrm{H}, \mathrm{NH}\right) ; \mathrm{MS}, m / z(\%) 587\left(\mathrm{M}^{+}\right.$, 2), 441 (30), 271 (43), 158 (100), 128 (43), 91 (31). Anal. Calcd. for $\mathrm{C}_{36} \mathrm{H}_{25} \mathrm{~N}_{7} \mathrm{O}_{2}$ (587.63): C, 73.58; $\mathrm{H}$, 4.29; N, 16.69. Found: C, 73.52; H, 4.15; N, 16.57 .

7-(4-Chlorophenyl)-2-(1H-indol-3-yl)-5-oxo-N-phenyl-4-(p-tolyl)-5,7-dihydropyrido[3,2-e][1,2,4]-triazolo[4,3-a] pyrimidine-9-carboxamide (19j). Yellow solid, (80\% yield), mp 279-281 ${ }^{\circ} \mathrm{C}$; IR (KBr): $v$ 3387, $3198(2 \mathrm{NH})$, 1683, $1642(2 \mathrm{C}=\mathrm{O}), 1597(\mathrm{C}=\mathrm{N}) \mathrm{cm}^{-1},{ }^{1} \mathrm{H}-\mathrm{NMR}\left(\mathrm{DMSO}-d_{6}\right): \delta 2.34\left(\mathrm{~s}, 3 \mathrm{H}, \mathrm{CH}_{3}\right), 7.02-8.34(\mathrm{~m}, 18 \mathrm{H}$, Ar-H and pyridine-H), 8.72 (s, $1 \mathrm{H}$, indole- $\left.\mathrm{H}_{2}\right), 11.13$ (br s, $\left.1 \mathrm{H}, \mathrm{NH}\right), 12.10$ (br s, $\left.1 \mathrm{H}, \mathrm{NH}\right) ; \mathrm{MS}, m / z(\%)$ $622\left(\mathrm{M}^{+}, 1\right), 341$ (38), 267 (100), 129 (35), 98 (52), 57 (63). Anal. Calcd. for $\mathrm{C}_{36} \mathrm{H}_{24} \mathrm{ClN}_{7} \mathrm{O}_{2}$ (622.07): C, 69.51; H, 3.89; N, 15.76. Found: C, 69.42; H, 3.81; N, 15.59 .

9-Acetyl-4-(4-chlorophenyl)-2-(1H-indol-2-yl)-7-phenylpyrido[3,2-e][1,2,4]triazolo[4,3-a]pyrimidin-5(7H)-one (19k). Yellow solid, (78\% yield), mp 271-273 ${ }^{\circ} \mathrm{C}$; IR (KBr): $v 3427(\mathrm{NH}), 1701,1674(2 \mathrm{C}=\mathrm{O}), 1589(\mathrm{C}=\mathrm{N})$ $\mathrm{cm}^{-1},{ }^{1} \mathrm{H}-\mathrm{NMR}$ (DMSO- $\left.d_{6}\right): \delta 2.49\left(\mathrm{~s}, 3 \mathrm{H}, \mathrm{CH}_{3}\right), 7.21-8.10(\mathrm{~m}, 14 \mathrm{H}, \mathrm{Ar}-\mathrm{H}$ and pyridine-H), $8.73(\mathrm{~s}, 1 \mathrm{H}$, indole- $\left.\mathrm{H}_{2}\right), 12.04$ (br s, $\left.1 \mathrm{H}, \mathrm{NH}\right)$; MS, $m / z$ (\%) $530\left(\mathrm{M}^{+}, 100\right), 515$ (53), 219 (47), 147 (87), 97 (21), 57 (79). Anal. Calcd. for $\mathrm{C}_{30} \mathrm{H}_{19} \mathrm{ClN}_{6} \mathrm{O}_{2}$ (530.96): $\mathrm{C}, 67.86 ; \mathrm{H}, 3.61 ; \mathrm{N}, 15.83$. Found: $\mathrm{C}, 67.69 ; \mathrm{H}, 3.54 ; \mathrm{N}, 15.71$. 
9-Acetyl-4-(4-chlorophenyl)-2-(1H-indol-2-yl)-7-(p-tolyl)pyrido[3,2-e][1,2,4]triazolo [4,3-a]pyrimidin5(7H)-one (191). Yellow solid, (78\% yield), mp 252-254 ${ }^{\circ} \mathrm{C}$; IR (KBr): $v 3403(\mathrm{NH}), 1705,1671(2 \mathrm{C}=\mathrm{O})$, $1583(\mathrm{C}=\mathrm{N}) \mathrm{cm}^{-1} ;{ }^{1} \mathrm{H}-\mathrm{NMR}\left(\mathrm{DMSO}-d_{6}\right): \delta 2.29\left(\mathrm{~s}, 3 \mathrm{H}, \mathrm{CH}_{3}\right), 2.46\left(\mathrm{~s}, 3 \mathrm{H}, \mathrm{CH}_{3}\right), 7.09-8.34(\mathrm{~m}, 13 \mathrm{H}, \mathrm{Ar}-\mathrm{H}$ and pyridine-H), 8.73 (s, $1 \mathrm{H}$, indole- $\left.\mathrm{H}_{2}\right), 12.10$ (br s, $\left.1 \mathrm{H}, \mathrm{NH}\right) ; \mathrm{MS}, m / z(\%) 544\left(\mathrm{M}^{+}, 3\right), 362$ (15), 303 (100), 227 (27), 117 (39), 55 (21). Anal. Calcd. for $\mathrm{C}_{31} \mathrm{H}_{21} \mathrm{ClN}_{6} \mathrm{O}_{2}$ (544.99): C, 68.32; $\mathrm{H}, 3.88 ; \mathrm{N}, 15.42$. Found: $\mathrm{C}, 68.25 ; \mathrm{H}, 3.69 ; \mathrm{N}, 15.31$.

\subsubsection{Alternate Synthesis of $\mathbf{1 9 a}, \mathbf{e}, \mathbf{i}$}

Equimolar amounts of 1-(1H-indol-3-yl)-3-( $p$-tolyl)prop-2-en-1-one (3a) $(0.261 \mathrm{~g}, 1 \mathrm{mmol})$ and 7-amino-1-phenyl-[1,2,4]triazolo[4,3-a]pyrimidin-5(1H)-one derivatives 20a,e, $\mathbf{i}(1 \mathrm{mmol})$ in acetic acid $(15 \mathrm{~mL})$, was refluxed for $10 \mathrm{~h}$ then cooled to room temperature. The solid precipitated was collected, washed with water, dried, and recrystallized from DMF to give the corresponding products, 19a,e, $\mathbf{i}$ which were identical in all respects ( $\mathrm{mp}$, mixed $\mathrm{mp}$ and IR spectra) with those obtained from reaction of thione $7 \mathbf{a}$ with hydrazonoyl chlorides $8 \mathbf{a}$,e, $\mathbf{i}$ but the $\%$ yields are $69 \%, 67 \%$, and $70 \%$, respectively.

\subsubsection{Synthesis of $N^{\prime}$-(1-(1H-Indol-3-yl)ethylidene)-2-cyanoacetohydrazide (22)}

To a solution of 2-cyanoacetohydrazide (21) $(1.0 \mathrm{~g}, 10 \mathrm{mmol}$ and 3-acetyl-1H-indole (1) $(0.159 \mathrm{~g}$, $1 \mathrm{mmol})$ in ethanol $(30 \mathrm{~mL})$, acetic acid $(2 \mathrm{~mL})$ was added. The reaction mixture was heated under reflux for $3 \mathrm{~h}$ then left to cool. The solid product formed was collected by filtration, dried, and then crystallized from the appropriate solvent as yellow solid, (76\% yield); mp 231-233 ${ }^{\circ} \mathrm{C}$; IR (KBr): $v 3402$ $(\mathrm{NH}), 2225(\mathrm{CN}) 1670(\mathrm{C}=\mathrm{O}), 1602(\mathrm{C}=\mathrm{N}) \mathrm{cm}^{-1},{ }^{1} \mathrm{H}-\mathrm{NMR}\left(\mathrm{DMSO}-d_{6}\right): \delta 2.57\left(\mathrm{~s}, 3 \mathrm{H}, \mathrm{CH}_{3}\right), 3.58(\mathrm{~s}, 2 \mathrm{H}$, $\left.\mathrm{CH}_{2}\right), 7.13-7.23(\mathrm{~m}, 2 \mathrm{H}, \mathrm{Ar}-\mathrm{H}), 7.47(\mathrm{~d}, J=6.9 \mathrm{~Hz}, 1 \mathrm{H}, \mathrm{Ar}-\mathrm{H}), 8.18(\mathrm{~d}, J=6.9 \mathrm{~Hz}, 1 \mathrm{H}, \mathrm{Ar}-\mathrm{H}), 8.29(\mathrm{~s}, 1 \mathrm{H}$, indole- $\left.\mathrm{H}_{2}\right), 10.42$ (br s, 1H, NH), 11.88 (br s, $\left.1 \mathrm{H}, \mathrm{NH}\right) ; \mathrm{MS}, m / z$ (\%) $240\left(\mathrm{M}^{+}, 17\right), 170$ (100), 153 (56), 183 (8), 125 (11), 70 (19), 55 (26). Anal. Calcd. for $\mathrm{C}_{13} \mathrm{H}_{12} \mathrm{~N}_{4} \mathrm{O}$ (240.26): $\mathrm{C}, 64.99 ; \mathrm{H}, 5.03 ; \mathrm{N}, 23.32$. Found $\mathrm{C}$, $64.85 ; \mathrm{H}, 5.01 ; \mathrm{N}, 23.22$.

\subsubsection{Synthesis of 3-(2-(1-(1H-Indol-3-yl)ethylidene)hydrazinyl)-2-cyano-3-oxo- $N$-phenylpropane} thioamide (25)

To a stirred solution of potassium hydroxide $(0.56 \mathrm{~g}, 10 \mathrm{mmol})$ in DMF $(30 \mathrm{~mL})$ was added compound 22 ( $2.40 \mathrm{~g}, 10 \mathrm{mmol})$. After stirring for 30 minutes, phenyl isothiocyanate (23) (1.35 g, $10 \mathrm{mmol}$ ) was added to the resulting mixture. Stirring was continued overnight. The reaction mixture was acidified with $\mathrm{HCl}$ and the solid product was filtered off, washed with water, and dried. Recrystallization from $\mathrm{EtOH}$ gave pure 25 as yellow solid, (70\% yield); mp $143-145^{\circ} \mathrm{C}$; $\mathrm{IR}(\mathrm{KBr}): v$ 3402, 3387, $3182(3 \mathrm{NH}), 2230(\mathrm{CN}) 1664(\mathrm{C}=\mathrm{O}), 1600(\mathrm{C}=\mathrm{N}) \mathrm{cm}^{-1},{ }^{1} \mathrm{H}-\mathrm{NMR}$ (DMSO- $\left.d_{6}\right): \delta 2.57(\mathrm{~s}, 3 \mathrm{H}$, $\left.\mathrm{CH}_{3}\right), 7.14-7.23(\mathrm{~m}, 2 \mathrm{H}, \mathrm{Ar}-\mathrm{H}), 7.46(\mathrm{~d}, J=6.9 \mathrm{~Hz}, 1 \mathrm{H}, \mathrm{Ar}-\mathrm{H}), 8.18(\mathrm{~d}, J=6.9 \mathrm{~Hz}, 1 \mathrm{H}, \mathrm{Ar}-\mathrm{H}), 8.29(\mathrm{~s}, 1 \mathrm{H}$, indole- $\mathrm{H}_{2}$ ), 9.85 (br s, $\left.1 \mathrm{H}, \mathrm{NH}\right), 10.40$ (br s, $\left.1 \mathrm{H}, \mathrm{NH}\right), 11.88$ (br s, $\left.1 \mathrm{H}, \mathrm{NH}\right), 13.11$ (s, $\left.1 \mathrm{H}, \mathrm{SH}\right) ; \mathrm{MS}, \mathrm{m} / z$ (\%) $375\left(\mathrm{M}^{+}, 56\right), 207$ (83), 165 (100), 119 (32), 77 (20). Anal. Calcd. for $\mathrm{C}_{20} \mathrm{H}_{17} \mathrm{~N}_{5} \mathrm{OS}$ (375.45): C, 63.98; $\mathrm{H}, 4.56 ; \mathrm{N}, 18.65$. Found $\mathrm{C}, 63.78 ; \mathrm{H}, 4.48 ; \mathrm{N}, 18.47$.

\subsubsection{Reaction of $\mathbf{2 5}$ with Hydrazonoyl Chlorides $8 \mathbf{a}, \mathbf{e}, \mathbf{i}$}

A mixture of 25 ( $0.375 \mathrm{~g}, 1 \mathrm{mmol})$ and $N^{\prime}$-phenylbenzohydrazonoyl chloride $\mathbf{8 a , e , \mathbf { i }}(1 \mathrm{mmol})$ in dioxane $(30 \mathrm{~mL})$ containing TEA $(0.7 \mathrm{~mL})$ was refluxed for $5 \mathrm{~h}$ (monitored by TLC), allowed to cool and the solid formed was collected, washed with $\mathrm{EtOH}$, dried, and recrystallized from DMF to give the respective 1,3,4-thiadiazole $27 \mathbf{a}-\mathbf{c}$.

N'-(1-(1H-Indol-3-yl)ethylidene)-2-(5-acetyl-3-phenyl-1,3,4-thiadiazol-2(3H)-ylidene)-2-cyanoaceto- hydrazide (27a). Yellow solid, (68\% yield); mp 191-193 ${ }^{\circ} \mathrm{C}$; IR (KBr): $v$ 3425, $3385(2 \mathrm{NH}), 2227(\mathrm{CN}), 1695,1664$ $(2 \mathrm{C}=\mathrm{O}), 1608(\mathrm{C}=\mathrm{N}) \mathrm{cm}^{-1} ;{ }^{1} \mathrm{H}-\mathrm{NMR}\left(\mathrm{DMSO}-d_{6}\right): \delta 2.47\left(\mathrm{~s}, 3 \mathrm{H}, \mathrm{CH}_{3}\right), 2.58\left(\mathrm{~s}, 3 \mathrm{H}, \mathrm{CH}_{3}\right), 7.19-8.25(\mathrm{~m}$, 9H, Ar-H), 8.68 (s, $1 \mathrm{H}$, indole- $\left.\mathrm{H}_{2}\right), 10.89$ (br s, $\left.1 \mathrm{H}, \mathrm{NH}\right), 11.93$ (br s, $\left.1 \mathrm{H}, \mathrm{NH}\right) ;{ }^{13} \mathrm{C}-\mathrm{NMR}\left(\mathrm{DMSO}-d_{6}\right) \delta$ : 14.0, 24.5, 74.0, 116.4, 110.0, 116.7, 118.7, 121.4, 124.8, 128.4, 136.3, 130.5, 135.0, 143.4, 148.4, 157.4, 164.0, 
189.9; MS, $m / z$ (\%) $442\left(\mathrm{M}^{+}, 16\right), 364$ (39), 275 (52), 215 (86), 107 (100), 81 (41), 43 (37). Anal. Calcd. for $\mathrm{C}_{23} \mathrm{H}_{18} \mathrm{~N}_{6} \mathrm{O}_{2} \mathrm{~S}$ (442.49): C, 62.43; H, 4.10; N, 18.99. Found C, 62.29; H, 4.03; N, 18.79.

Ethyl5-(2-(2-(1-(1H-Indol-3-yl)ethylidene)hydrazinyl)-1-cyano-2-oxoethylidene)-4-phenyl-4,5-dihydro-1,3,4thiadiazole-2-carboxylate (27b). Yellow solid, (68\% yield); mp 191-193 ${ }^{\circ} \mathrm{C}$; IR (KBr): $v$ 3425, $3385(2 \mathrm{NH})$, $2227(\mathrm{CN}), 1695,1664(2 \mathrm{C}=\mathrm{O}), 1608(\mathrm{C}=\mathrm{N}) \mathrm{cm}^{-1} ;{ }^{1} \mathrm{H}-\mathrm{NMR}\left(\mathrm{DMSO}-d_{6}\right): \delta 1.30\left(\mathrm{t}, J=7.1 \mathrm{~Hz}, 3 \mathrm{H}, \mathrm{CH}_{3}\right)$, $2.55\left(\mathrm{~s}, 3 \mathrm{H}, \mathrm{CH}_{3}\right), 4.27\left(\mathrm{q}, J=7.1 \mathrm{~Hz}, 2 \mathrm{H}, \mathrm{CH}_{2}\right), 7.10-8.29(\mathrm{~m}, 9 \mathrm{H}, \mathrm{Ar}-\mathrm{H}), 8.69\left(\mathrm{~s}, 1 \mathrm{H}\right.$, indole- $\left.\mathrm{H}_{2}\right), 10.88$ (br s, $1 \mathrm{H}, \mathrm{NH}), 11.97$ (br s, $1 \mathrm{H}, \mathrm{NH}){ }^{13}{ }^{13} \mathrm{C}-\mathrm{NMR}$ (DMSO-d 6 ) $\delta:$ MS, 14.0, 24.5, 74.0, 110.0, 110.5, 118.9, 120.4, 121.5, 125.1, 130.3, 130.5, 133.0, 143.4, 148.5, 157.0, 164.0, 189.8; $\mathrm{m} / \mathrm{z}(\%) 472\left(\mathrm{M}^{+}, 15\right), 412(37), 250$ (43), 139 (100), 108 (29), 43 (40). Anal. Calcd. for $\mathrm{C}_{24} \mathrm{H}_{20} \mathrm{~N}_{6} \mathrm{O}_{3} \mathrm{~S}$ (472.52): C, 61.00; H, 4.27; N, 17.79. Found C, 61.07; H, 4.17; N, 17.64 .

5-(2-(2-(1-(1H-Indol-3-yl)ethylidene)hydrazinyl)-1-cyano-2-oxoethylidene)-N,4-diphenyl-4,5-dihydro-1,3,4thiadiazole-2-carboxamide (27c). Yellow solid, (67\% yield); mp 276-278 ${ }^{\circ} \mathrm{C}$; IR (KBr): $v$ 3417, 3363, 3197 (3NH), $2230(\mathrm{CN}), 1674,1627(2 \mathrm{C}=\mathrm{O}), 1601(\mathrm{C}=\mathrm{N}) \mathrm{cm}^{-1} ;{ }^{1} \mathrm{H}-\mathrm{NMR}$ (DMSO- $\left.d_{6}\right) \delta: 2.55\left(\mathrm{~s}, 3 \mathrm{H}, \mathrm{CH}_{3}\right)$, 7.06-8.28 (m, 14H, Ar-H), 8.47 (s, 1H, indole- $\left.\mathrm{H}_{2}\right), 9.87$ (br s, $\left.1 \mathrm{H}, \mathrm{NH}\right), 10.66$ (br s, $\left.1 \mathrm{H}, \mathrm{NH}\right), 11.49$ (br s, $1 \mathrm{H}, \mathrm{NH}) ; \mathrm{MS}, m / z(\%) 519\left(\mathrm{M}^{+}, 100\right), 372$ (53), 266 (38), 137 (29), 120 (57), 43 (40). Anal. Calcd. for $\mathrm{C}_{28} \mathrm{H}_{21} \mathrm{~N}_{7} \mathrm{O}_{2} \mathrm{~S}$ (519.58): C, 64.73; H, 4.07; N, 18.87. Found C, 64.58; H, 4.03; N, 18.72.

\subsection{Antitumor Activity Assay}

The tested human carcinoma cell lines were obtained from the American Type Culture Collection (ATCC, Rockville, MD, USA). The cells were grown on RPMI-1640 medium supplemented with $10 \%$ heat inactivated fetal calf serum, $1 \%$ L-glutamine, and $50 \mu \mathrm{g} / \mathrm{mL}$ gentamycin. The cells were maintained at $37^{\circ} \mathrm{C}$ in a humidified atmosphere with $5 \% \mathrm{CO}_{2}$ incubator (Shel lab 2406, New York, NY, USA) and were sub-cultured two to three times a week. For antitumor assays, the tumor cell lines were suspended in medium at concentration $5 \times 10^{4}$ cell/well in Corning ${ }^{\circledR}$ 96-well tissue culture plates, then incubated for $24 \mathrm{~h}$. The tested compounds were then added into 96-well plates (six replicates) to achieve eight concentrations for each compound (started from 200 to $1.56 \mu \mathrm{g} / \mathrm{mL}$ ). Six vehicle controls with media or $0.1 \%$ DMSO were run for each 96 -well plate as a control. After incubating for $24 \mathrm{~h}$, the numbers of viable cells were determined by the MTT assay. Briefly, the media was removed from the 96-well plate and replaced with $100 \mu \mathrm{L}$ of fresh culture RPMI 1640 medium without phenol red then $10 \mu \mathrm{L}$ of the $12 \mathrm{mM}$ MTT (3-[4,5-dimethylthiazol- 2-yl]-2,5-diphenyltetrazolium bromide (MTT; Sigma Chemical Co., St. Louis, MO, USA) stock solution ( $5 \mathrm{mg}$ of MTT in $1 \mathrm{~mL}$ of PBS) to each well including the untreated controls. The 96-well plates were then incubated at $37{ }^{\circ} \mathrm{C}$ and $5 \% \mathrm{CO}_{2}$ for $4 \mathrm{~h}$. An $85 \mu \mathrm{L}$ aliquot of the media was removed from the wells, and $50 \mu \mathrm{L}$ of DMSO was added to each well and mixed thoroughly with the pipette and incubated at $37^{\circ} \mathrm{C}$ for $10 \mathrm{~min}$. Then, the optical density was measured at $590 \mathrm{~nm}$ with the microplate reader ((SunRise, TECAN, Inc, Männedorf, Switzerland) to determine the number of viable cells and the percentage of viability was calculated as [1 - (ODt/ODc)] $\times 100 \%$, where ODt is the mean optical density of wells treated with the tested sample and ODc is the mean optical density of untreated cells. The relation between surviving cells and drug concentration is plotted to get the survival curve of each tumor cell line after treatment with the specified compound. The $50 \%$ inhibitory concentration $\left(\mathrm{IC}_{50}\right)$, the concentration required to cause toxic effects in $50 \%$ of intact cells, was estimated from graphic plots of the dose response curve for each concentration using Graphpad Prism software (San Diego, CA, USA) [47,48].

\section{Conclusions}

3-Acetylindole proved to be a useful precursor for synthesis of various 1,3-thiazoles, 1,2,4-thiadiazoles and pyrido[3,2-e][1,2,4]triazolo[4,3-a]pyrimidin-5(7H)-one. The structures of the newly synthesized compounds were confirmed by spectral data and elemental analyses. Some of the new compounds were tested in vitro against the MCF-7 human breast carcinoma cell line and compared 
with doxorubicin as the standard, using the MTT viability assay. Most of the tested compounds were found to have moderate to high anticancer activity.

Acknowledgments: The authors would like to thank the Chemistry Department, Faculty of Science, Cairo University for their financial support to facilitate the publication of this study.

Author Contributions: A.O.A., S.M.G., N.A.A., and S.M.K. conceived, designed the experiments, performed the experiments, analyzed the data, and contributed reagents/materials/analysis tools. A.O.A. and S.M.G. wrote and approved the final manuscript.

Conflicts of Interest: The authors declare no conflict of interest.

\section{References}

1. Parmentier, J.G.; Poissonnet, G.; Goldstein, S. Practical Syntheses of 5-Trifluoromethyl-1H-indoles. Heterocycles 2002, 56, 465-476.

2. Black, D.S.; Craig, D.C.; Rezaie, R. Synthesis of mixed heterocalixarenes from benzofuranyl methanols and activated indoles. Chem. Commun. 2002, 8, 810-811. [CrossRef]

3. Gaifa, L.; Wayne, K.N. Synthesis of novel indole analogues of mycophenolic acid as potential antineoplastic agents. Tetrahedron 2000, 56, 2583-2590.

4. Aiello, F.; Valacchi, G. Synthesis and Evaluation of Indole Based Molecules for Treatment of Oxidative Stress Related Diseases. Curr. Top. Med. Chem. 2014, 14, 2576-2589. [CrossRef] [PubMed]

5. Broadbent, T.A.; Broadbent, H.S. The chemistry and pharmacology of indole-3-carbinol (indole-3-methanol) and 3-(methoxymethyl)indole. Part I. Curr. Med. Chem. 1998, 5, 337-352. [PubMed]

6. Riby, J.E.; Chang, G.H.; Firestone, G.L.; Bjeldanes, L.F. Ligand-independent activation of estrogen receptor function by 3,3'-diindolylmethane in human breast cancer cells. Biochem. Pharmacol. 2000, 60, 167-177. [CrossRef]

7. Hargrave, K.D.; Hess, F.K.; Oliver, J.T. N-(4-Substituted-thiazolyl)oxamic acid derivatives, new series of potent, orally active antiallergy agents. J. Med. Chem. 1983, 26, 1158-1163. [CrossRef] [PubMed]

8. Patt, W.C.; Hamilton, H.W.; Taylor, M.D.; Ryan, M.J.; Taylor, D.G., Jr.; Connolly, C.J.C.; Doherty, A.M.; Klutchko, S.R.; Sircar, I.; Steinbaugh, B.A.; et al. Structure-activity relationships of a series of 2-amino-4-thiazole containing renin inhibitors. J. Med. Chem. 1992, 35, 2562-2572. [CrossRef] [PubMed]

9. Sharma, R.N.; Xavier, F.P.; Vasu, K.K.; Chaturvedi, S.C.; Pancholi, S.S. Synthesis of 4-benzyl-1,3-thiazole derivatives as potential anti-inflammatory agents: An analogue-based drug design approach. J. Enzym. Inhib. Med. Chem. 2009, 24, 890-897. [CrossRef] [PubMed]

10. Jaen, J.C.; Wise, L.D.; Caprathe, B.W.; Tecle, H.; Bergmeier, S.; Humblet, C.C.; Heffner, T.G.; Meltzner, L.T.; Pugsley, T.A. 4-(1,2,5,6-Tetrahydro-1-alkyl-3-pyridinyl)-2-thiazolamines: A novel class of compounds with central dopamine agonist properties. J. Med. Chem. 1990, 33, 311-317. [CrossRef] [PubMed]

11. Tsuji, K.; Ishikawa, H. Synthesis and anti-pseudomonal activity of new 2-isocephems with a dihydroxypyridone moiety at C-7. Bioorg. Med. Chem. Lett. 1994, 4, 1601-1606. [CrossRef]

12. Bell, F.W.; Cantrell, A.S.; Hoegberg, M.; Jaskunas, S.R.; Johansson, N.G.; Jordon, C.L.; Kinnick, M.D.; Lind, P.; Morin, J.M.; Noreen, R.; et al. Phenethylthiazolethiourea (PETT) compounds, a new class of HIV-1 reverse transcriptase inhibitors. 1. Synthesis and basic structure-activity relationship studies of PETT analogs. J. Med. Chem. 1995, 38, 4929-4936. [CrossRef] [PubMed]

13. Ergenc, N.; Capan, G.; Gunay, N.S.; Ozkirimli, S.; Gungor, M.; Ozbey, S.; Kendi, E. Synthesis and hypnotic activity of new 4-thiazolidinone and 2-thioxo-4,5-imidazolidinedione derivatives. Arch. Pharm. Pharm. Med. Chem. 1999, 332, 343-347. [CrossRef]

14. Carter, J.S.; Kramer, S.; Talley, J.J; Penning, T.; Collins, P.; Graneto, M.J.; Seibert, K.; Koboldt, C.; Masferrer, J.; Zweifel, B. Synthesis and activity of sulfonamide-substituted 4,5-diaryl thiazoles as selective cyclooxygenase-2 inhibitors. Bioorg. Med. Chem. Lett. 1999, 9, 1171-1174. [CrossRef]

15. Badorc, A.; Bordes, M.F.; de Cointet, P.; Savi, P.; Bernat, A.; Lale, A.; Petitou, M.; Maffrand, J.P.; Herbert, J.M. New orally active non-peptide fibrinogen receptor (GpIIb-IIIa) antagonists: Identification of ethyl 3-[N-[4-[4-amino[(ethoxycarbonyl) imino]methyl]phenyl]-1,3-thiazol-2-yl]- $N$-[1-(ethoxycarbonyl)methyl] piperid-4-yl]amino]propionate (SR 121787) as a potent and long-acting antithrombotic agent. J. Med. Chem. 1997, 40, 3393-3401. [PubMed] 
16. Rudolph, J.; Theis, H.; Hanke, R.; Endermann, R.; Johannsen, L.; Geschke, F.U. Seco-Cyclothialidines: New concise synthesis, inhibitory activity toward bacterial and human DNA topoisomerases, and antibacterial properties. J. Med. Chem. 2001, 44, 619-626. [CrossRef] [PubMed]

17. Astakhov, A.V.; Chernyshev, V.M. Molecular structure of 3-amino[1,2,4]triazolo-[4,3-a] pyrimidin-5-one in various tautomeric forms: Investigation by DFT and QTAIM methods. Chem. Heterocycl. Compd. 2014, 50, 319-326. [CrossRef]

18. Gomha, S.M. A facile one-pot synthesis of 6,7,8,9-tetrahydrobenzo[4,5]thieno[2,3- $d]-1,2,4$-triazolo [4,5-a]pyrimidin-5-ones. Monatshefte Chem. 2009, 140, 213-220. [CrossRef]

19. Fares, M.; Abou-Seri, S.M.; Abdel-Aziz, H.A.; Abbas, S.E.S.; Youssef, M.M.; Eladwy, R.A. Synthesis and antitumor activity of pyrido[2,3-d]pyrimidine and pyrido[2,3- $d][1,2,4]$ triazolo[4,3- $a]$ pyrimidine derivatives that induce apoptosis through G(1) cell-cycle arrest. Eur. J. Med. Chem. 2014, 83, 155-166. [CrossRef] [PubMed]

20. Gomha, S.M.; Ahmed, S.A.; Abdelhamid, A.O. Synthesis and cytotoxicity evaluation of some novel thiazoles, thiadiazoles, and pyrido[2,3- $d][1,2,4]$ triazolo[4,3-a]pyrimidin-5(1H)-one incorporating triazole moiety. Molecules 2015, 20, 1357-1376. [CrossRef] [PubMed]

21. Liu, X.H.; Sun, Z.H.; Yang, M.Y.; Tan, C.X.; Weng, J.Q.; Zhang, Y.G.; Ma, Y. Microwave assistant one pot synthesis, crystal structure, antifungal activities and 3D-QSAR of novel 1,2,4-triazolo[4,3-a]pyridines. Chem. Biol. Drug Des. 2014, 84, 342-347. [CrossRef] [PubMed]

22. Gomha, S.M.; Badrey, M.G. Ecofriendly regioselective one-pot synthesis of chromeno[4,3-d] $[1,2,4]$ triazolo [4,3-a]pyrimidine. Eur. J. Chem. 2013, 4, 180-184. [CrossRef]

23. Zhang, L.J.; Yang, M.Y.; Sun, Z.H.; Tan, C.X.; Weng, J.Q.; Wu, H.K.; Liu, X.H. Synthesis and antifungal activity of 1,3,4-thiadiazole derivatives containing pyridine group. Lett. Drug Des. Discov. 2014, 11, 1107-1111. [CrossRef]

24. Gomha, S.M.; Khalil, K.D.; El-Zanate, A.M.; Riyadh, S.M. A facile green synthesis and anti-cancer activity of bis-arylhydrazononitriles, triazolo[5,1-c][1,2,4]triazine, and 1,3,4-thiadiazoline. Heterocycles 2013, 87, 1109-1120.

25. Yan, S.L.; Yang, M.Y.; Sun, Z.H.; Min, L.J.; Tan, C.X.; Weng, J.Q.; Wu, H.K.; Liu, X.H. Synthesis and antifungal activity of 1,2,3-thiadiazole derivatives containing 1,3,4-thiadiazole moiety. Lett. Drug Des. Discov. 2014, 11, 940-943. [CrossRef]

26. Tong, J.Y.; Sun, N.B.; Wu, H.K.; Liu, X.H. Synthesis, crystal structure and biological activity of N-(5-(Otolyl)-1,3,4-thiadiazol-2-yl)cyclopropanecarboxamide. J. Chem. Soc. Pak. 2013, 35, 1349-1353.

27. Gomha, S.M.; Salah, T.A.; Abdelhamid, A.O. Synthesis, characterization and pharmacological evaluation of some novel thiadiazoles and thiazoles incorporating pyrazole moiety as potent anticancer agents. Monatshefte Chem. 2015, 146, 149-158. [CrossRef]

28. Li, Z.; Wang, X.; Da, Y. Synthesis of 2-(5-(2-chlorophenyl)-2-furoylamino)-5-aryloxymethyl- 1,3,4-thiadiazoles under microwave irradiation. Synth. Commun. 2001, 31, 1829-1836. [CrossRef]

29. Gomha, S.M.; Abdel-Aziz, H.A. Synthesis of new heterocycles derived from 3-(3-methyl-1H-indol-2-yl)-3oxopropanenitrile as potent antifungal agents. Bull. Korean Chem. Soc. 2012, 33, 2985-2990. [CrossRef]

30. Liu, X.; Shi, Y.; Ma, Y.; Zhang, C.; Dong, W.; Pan, L.; Wang, B.; Li, Z. Synthesis, antifungal activities and 3D-QSAR study of N-(5-substituted-1,3,4-thiadiazol-2-yl)cyclopropane carboxamides. Eur. J. Med. Chem. 2009, 44, 2782-2786. [CrossRef] [PubMed]

31. Ahmad, T.; Singh, A.K.; Jaiswal, N.; Singh, D. Synthesis and pharmacological activity of 1,3,4-thiadiazole derivatives: A review. Int. Res. J. Pharm. 2012, 3, 70-82.

32. Gomha, S.M.; Riyadh, S.M. Synthesis under microwave irradiation of $[1,2,4]$ triazolo[3,4- $b][1,3,4]$ thiadiazoles and other diazoles bearing indole moieties and their antimicrobial evaluation. Molecules 2011, 16, 8244-8256. [CrossRef] [PubMed]

33. Qiu, X.L.; Li, G.; Wu, G.; Zhu, J.; Zhou, L.; Chen, P.L.; Chamberlin, A.R.; Lee, W.H. Synthesis and biological evaluation of a series of novel inhibitor of Nek2/Hec1 analogues. J. Med. Chem. 2009, 52, 1757-1767. [CrossRef] [PubMed] 
34. Tsoua, H.; MacEwan, G.; Birnberg, G.; Grosu, G.; Bursavich, M.G.; Bard, J.; Brooijmansa, N.; Toral-Barzab, L.; Hollanderb, I.; Mansoura, T.S.; et al. Discovery and optimization of 2-(4-substituted-pyrrolo [2,3-b] pyridin-3-yl)methylene-4-hydroxybenzofuran-3(2H)-ones as potent and selective ATP-competitive inhibitors of the mammalian target of rapamycin (mTOR). Bioorg. Med. Chem. Lett. 2010, 20, 2321-2325. [CrossRef] [PubMed]

35. Mavrova, A.T.; Wesselinova, D.; Tsenov, Y.A.; Denkova, P. Synthesis, cytotoxicity and effects of some 1,2,4-triazole and 1,3,4-thiadiazole derivatives on immunocompetent cells. Eur. J. Med. Chem. 2009, 44, $63-69$. [CrossRef] [PubMed]

36. Oleson, J.J.; Slobada, A.; Troy, W.P.; Halliday, S.L.; Landes, M.J.; Angier, R.B.; Semb, J.; Cyr, K.; Williams, J.H. The carcinostatic activity of some 2-amino-1,3,4-thiadiazoles. J. Am. Chem. Soc. 1955, 77, 6713-6714. [CrossRef]

37. Matysiak, J.; Opolski, A. Synthesis and antiproliferative activity of N-substituted 2-amino-5-(2,4dihydroxyphenyl)-1,3,4-thiadiazoles. Bioorg. Med. Chem. 2006, 14, 4483-4489. [CrossRef] [PubMed]

38. Ismail, M.M.F.; Khalifa, N.M.; Fahmy, H.H.; Nossier, E.S.; Abdulla, M. Design, docking, and synthesis of some new pyrazoline and pyranopyrazole derivatives as anti-inflammatory agents. J. Heterocycl. Chem. 2014, 51, 450-458. [CrossRef]

39. Manna, F.; Chimenti, F.; Bolasco, A.; Bizzarri, B.; Filippelli, W.; Filippelli, A.; Gagliardi, L. Anti-inflammatory, analgesic and antipyretic 4,6-disubstituted 3-cyano-2-aminopyridines. Eur. J. Med. Chem. 1999, 34, $245-254$. [CrossRef]

40. Butler, R.N. Comprehensive Heterocyclic Chemistry; Katritzky, A.R., Rees, C.W., Scriven, E.F.V., Eds.; Pergamon Press: New York, NY, USA, 1996; Volume 4, pp. 621-678.

41. Huisgen, R.; Grashey, R.; Seidel, M.; Knupfer, H.; Schmidt, R. 1,3-Dipolare additionen, III. Umsetzungen des diphenylnitrilimins mit carbonyl und thiocarbonyl-verbindungen. Justus Liebigs Ann. Chem. 1962, 658, 169-180. [CrossRef]

42. Mosselhi, M.A.N. A convenient synthesis of novel derivatives of pyrido[2,3- $d][1,2,4]$ triazolo[ $[4,3-a]$ pyrimidine-5,6-dione. Monatshefte Chem. 2002, 133, 1297-1304. [CrossRef]

43. Eweiss, N.F.; Osman, A. Synthesis of heterocycles-2. New routes to acetylthiadiazolines and arylazothiazoles. J. Heterocycl. Chem. 1980, 17, 1713-1717. [CrossRef]

44. Shawali, A.S.; Osman, A. Reaction of dimethylphenacylsulfonium bromide with $N$-nitrosoacetaryl-amides and reactions of the products with nucleophiles. Bull. Chem. Soc. Jpn. 1976, 49, 321-324. [CrossRef]

45. Shawali, A.S.; Osman, A. Synthesis and reactions of phenylcarbamoyl-arylhydrazidic chlorides. Tetrahedron 1971, 27, 2517-2528. [CrossRef]

46. Asiri, A.M.; Zayed, M.E.M.; Ng, S.W. Ethyl (Z)-2-chloro-2-(2-phenylhydrazin-1-ylidene)acetate. Acta Crystallogr. 2011, 67, o1962. [CrossRef] [PubMed]

47. Mosmann, T. Rapid colorimetric assay for cellular growth and survival: Application to proliferation and cytotoxicity assays. J. Immunol. Methods 1983, 65, 55-63. [CrossRef]

48. Fu, L.; Feng, X.; Wang, J.-J.; Xun, Z.; Hu, J.-D.; Zhang, J.-J.; Zhao, Y.-W.; Huang, Z.-B.; Shi, D.-Q. Efficient Synthesis and Evaluation of Antitumor Activities of Novel Functionalized 1,8-Naphthyridine Derivatives. ACS Comb. Sci. 2015, 17, 24-31. [CrossRef] [PubMed]

Sample Availability: Samples of the synthsized compounds are available from the authors.

(C) 2016 by the authors; licensee MDPI, Basel, Switzerland. This article is an open access article distributed under the terms and conditions of the Creative Commons Attribution (CC-BY) license (http://creativecommons.org/licenses/by/4.0/). 